TOMA DE DECISIONES EN ADOELSCENTES COLOMBIANOS POLICONSUMIDORES

TESIS DE MAESTRÍA

JAVIER SEBASTIÁN ROZO BURITICA

UNIVERSIDAD CATÓLICA DE COLOMBIA

FACULTAD DE PSICOLOGÍA

MAESTRÍA EN PSICOLOGÍA

Bogotá, D. C. septiembre y 2021 
TOMA DE DECISIONES EN ADOLESCENTES COLOMBIANOS POLICONSUMIDORES

TESIS DE MAESTRÍA

JAVIER SEBASTIÁN ROZO BURITICA 460398

MARÍA FERNANDA COBO CHARRY

Director

UNIVERSIDAD CATÓLICA DE COLOMBIA

FACULTAD DE PSICOLOGÍA

MAESTRÍA EN PSICOLOGÍA

Bogotá, D. C. septiembre y 2021 


\section{(1)@()}

\section{Atribución-NoComercial-Compartirlgual 4.0 Internacional (CC BY-NC-SA 4.0)}

This is a human-readable summary of (and not a substitute forl) the license. Advartencia.

\section{Usted es libre de:}

Compartir - coplary redistribuir el material en caalquier medio o formato

Adaptar - remeaclar, transformar y construit a partir del material

La licenciante no puede revocar estas libertades en tanto vated sigs

lostéminas de la hicencia

\section{Bajo los siguientes términos:}

Atribución - Usted debe dar críditus de manern adecuada, brindar un enlace a la licencia, e indicar si se ham realizado cambios, Puede hacerlo en cualquier forma razonable, pero no de forma tal que sugiera que usted o su uso tienen el apoyo de la licenciante.

NoComercial - Usted no puede hacer uso del material con propósitos comerciales.

Compartirigual - Si remexcla, transforma o crea a partir del materiat, debe distribuir su contribución bajo la larnisma tioncia def original.

No hay restricciones adicionales - No puede aplicar términos legales ni medidas tecnolópicas cue restrinjan legalmente a otras a hacer cualquier uso permitide por la Hicencia. 


\title{
FACULTAD DE PSICOLOGIA
}

\author{
PROGRAMA MAESTRIA EN PSICOLOGIA
}

ACTA DE EVALUACIÓN Y CALIFICACIÓN DE TRABAJOS DE GRADO

En Bogota a las veinilinueve (29) dís del mes de septiembre del afín 2021, se reunieron los suscritos miembros del Comitê de Maeshia en Psioglogia, para evaluar y oborgar la calificacion final al trabejo de grado presentado por el estudiante JAVIER SEBASTIAN ROZO BURITICA, titLlado: "TOMA DE DECISIONES EN ADOLESCENTES COLOMBIANOS POLICONSUMIDORES".

Una vez revisada el acta del examen de sustentacion y de conlonidad con los criterios establecidos por la direcoión del programa, se ratifiod la calificación de los jurados dada en la sustentacón publica:

\section{APROBADA}

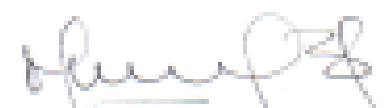

Dra. IDALY GARRETO GALEANO Decana

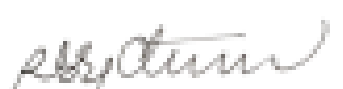

RUDQY JULIETH CASTRO OSORIO

Directona Maestria en Peicología 
"Las opiniones expresadas en este trabajo son responsabilidad de sus autores, la Facultad de Psicología solo ha verificado el cumplimiento de las condiciones mínimas de rigor científico y de manejo ético".

Reglamento Interno

Artículo, 65 


\section{AGRADECIMIENTOS}

Agradezco inicialmente a la Universidad Católica de Colombia, por darme la oportunidad de hacer parte de tan prestigiosa institución. A mis mentoras Sandra Camelo y María Fernanda Cobo quienes acompañaron mi proceso investigativo, entendieron y se adaptaron a las condiciones que se atravesaron durante el camino. 


\section{DEDICATORIA}

Dedico este proceso a mi familia y a María Fernanda Piragauta, por todo el apoyo, acompañamiento, lealtad e incondicionalidad durante este proceso. 


\section{TABLA DE CONTENIDO}

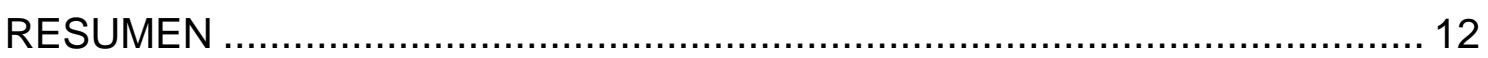

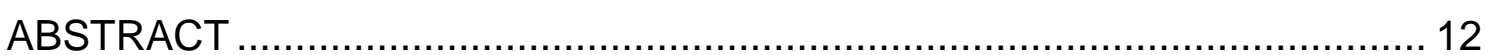

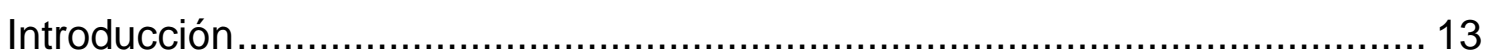

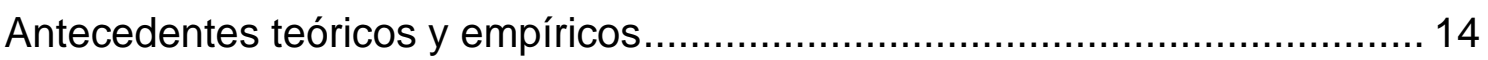

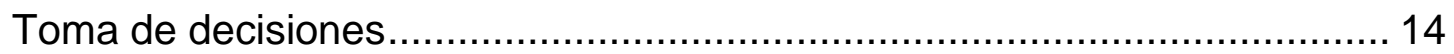

Mecanismos cerebrales en la toma de decisiones ....................................... 18

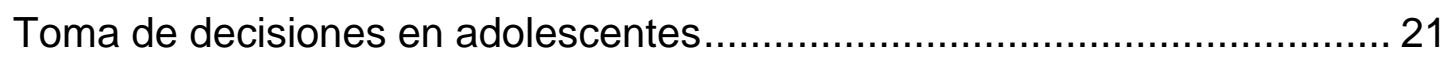

Hipótesis del marcador somático en la toma de decisiones ........................ 25

Sustancias Psicoactivas y mecanismos neuroquímicos .............................. 33

Modelos Neuropsicológicos de la adicción implicaciones en la toma de decisiones........................................................................................ 36 Modelo basado en la sensibilización de los mecanismos motivacionales. 36 Modelo de daño en la atribución de relevancia y la inhibición de respuesta

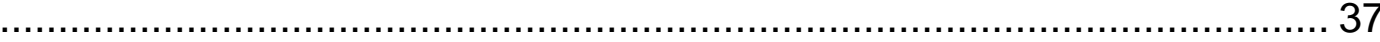

Modelos basados en la transición entre impulsividad y compulsión ..........37

Modelo de vulnerabilidades en los procesos de decisión ......................... 37 Modelo de alteraciones en la toma de decisiones (marcadores somáticos)

Toma de decisiones y consumo de sustancias psicoactivas ....................... 39

La toma de decisiones y el lowa Gambling Task (IGT) ............................. 42

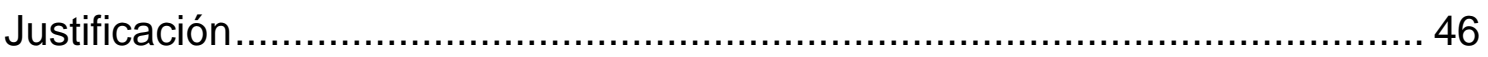

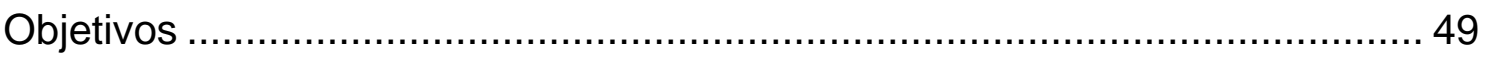

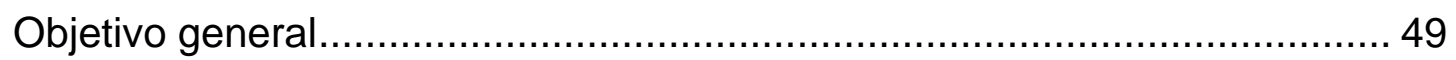

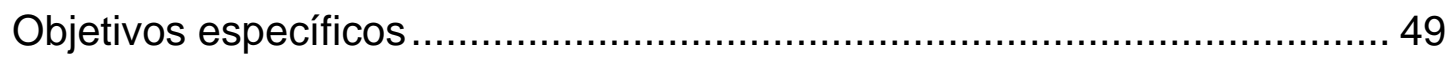

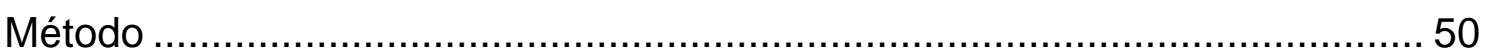

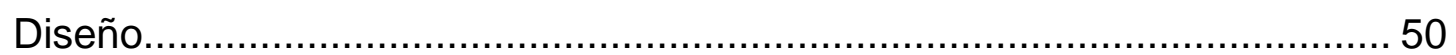

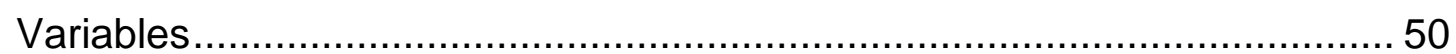

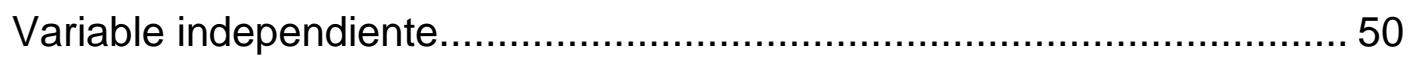

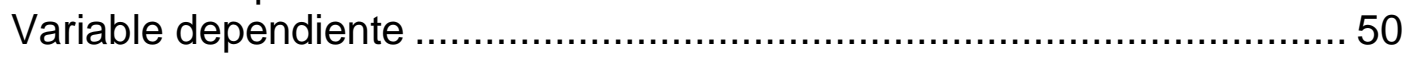

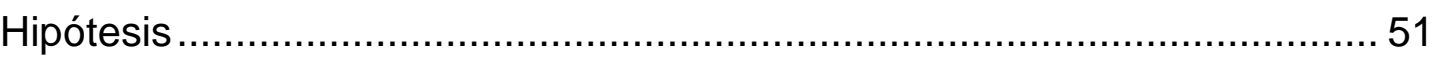

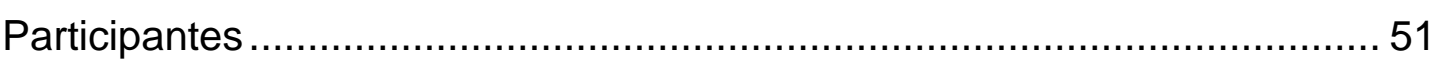

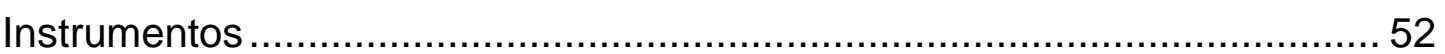

Historia clínica......................................................................... 52

Prueba de detección de consumo de alcohol, tabaco y sustancias ASSIST

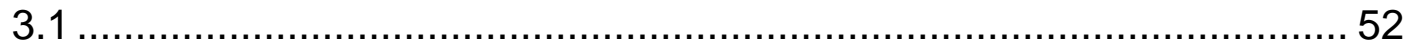




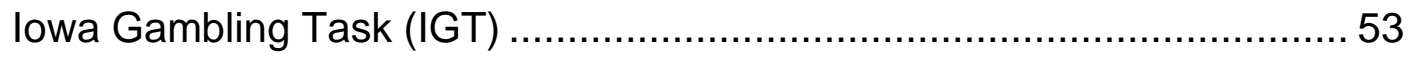

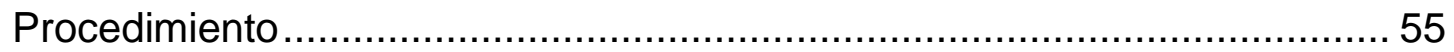

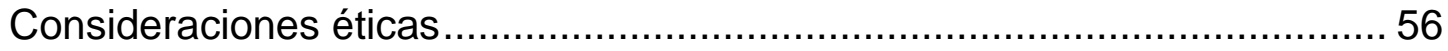

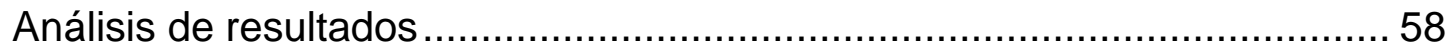

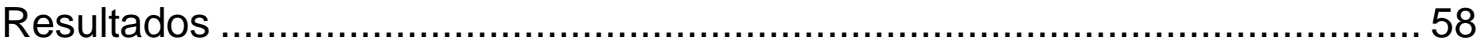

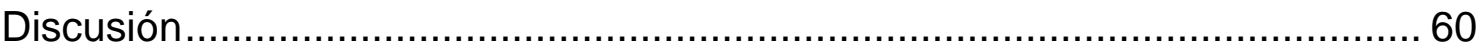

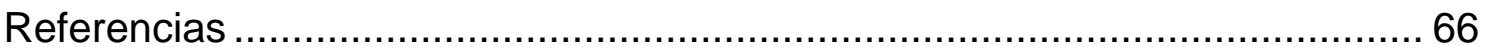

Apéndices 


\section{LISTA DE TABLAS}

Tabla 1. Datos sociodemográficos descriptivos en función del grupo de policonsumidores y no consumidores

Tabla 2. Prueba de normalidad Shapiro-Wilk para la elección de mazos del IGT

Tabla 3. Prueba T-Student del grupo de policonsumidores y no consumidores en el lowa Gambling Task 


\section{LISTA DE APÉNDICES}

Apéndice A. Formato de Historia Clínica. 85 Apéndice B. Prueba de detección de alcohol, tabaco y sustancias (ASSIST V 3.1) 89 Apéndice C. Consentimiento informado para la participación de la investigación Apéndice D. Asentimiento informado para la participación de la investigación

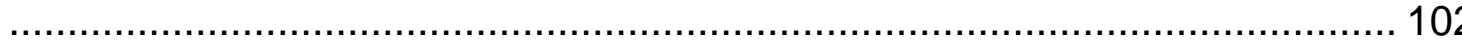

Apéndice E. Protección de datos personales- HABEAS DATA ....................... 103 Apéndice F. Tabla preprogramada lowa Gambling Task .............................. 104 


\title{
TOMA DE DECISIONES EN ADOLESCENTES COLOMBIANOS POLICONSUMIDORES
}

\author{
Javier Sebastián Rozo Buriticá y María Fernanda Cobo Charry \\ Universidad Católica de Colombia
}

\begin{abstract}
RESUMEN
El presente estudio tuvo como objetivo comparar el rendimiento en el proceso toma de decisiones de 14 adolescentes colombianos, hombres y mujeres, en edades comprendidas entre 16 y 17 años distribuidos en dos grupos, el primer grupo (casos) se conformó por siete adolescentes policonsumidores de sustancias psicoactivas y el segundo (grupo control) fue conformado por 7 adolescentes con características sociodemográficas similares y sin consumo de sustancias psicoactivas. Se utilizó un diseño de tipo comparativo ex post facto, se aplicaron tres instrumentos: a) historia clínica para identificar las variables de inclusión y exclusión del estudio; b) prueba de detección de consumo de alcohol, tabaco y otras sustancias (ASSIST) la cual permite establecer el nivel de riesgo de una sustancia consumida y c) lowa Gambling Task (IGT) que busca evaluar el proceso de toma de decisiones en la que se aprende por medio de ensayo y error las consecuencias a corto plazo de una elección sea beneficiosa o no. A partir de la medición de las variables y el tipo de distribución, se realizó el análisis estadístico de normalidad a través del estadístico Shapiro-Wilk para cada grupo, luego se implementó la prueba $t$ Student. Se encontró que los adolescentes policonsumidores tienen menor rendimiento en el proceso de toma de decisiones, eligiendo con mayor frecuencia el mazo desventajoso A, mientras que, los adolescentes no consumidores se inclinaban por el mazo ventajoso C. Sin embargo, no hubo una diferencia significativa en la elección de los mazos B y $C$ entre ambos grupos Lo anterior evidencia que los adolescentes policonsumidores presentan mayor inclinación en la toma de decisiones impulsivas y riesgosas con respecto a los no consumidores. Se considera pertinente realizar investigaciones que permitan ampliar y respaldar los resultados encontrados.

Palabras clave: Toma de decisiones TG010404; Adolescentes NA090406; Consumo de drogas TR090604-TR090602
\end{abstract}

\section{ABSTRACT \\ Decision making in Colombian adolescents polyconsumers}

The present study aimed to compare the performance in the decision-making process of 14 Colombian adolescents, men and women, between the ages of 16 and 17, distributed in two groups, the first group (cases) was made up of seven adolescent polydrivers. of psychoactive substances and the second (control group) was made up of 7 adolescents with similar sociodemographic characteristics and without consumption of psychoactive substances. An ex post facto comparative type design was used, three instruments were applied: a) clinical history to identify the study inclusion and exclusion variables; b) alcohol, tobacco and other substance use detection test (ASSIST) which allows to establish the risk level of a substance consumed and c) lowa Gambling Task (IGT) which seeks to evaluate the decision-making process in which the learn by trial and error the short-term consequences of a choice whether it is beneficial or not. From the measurement of the variables and the type of distribution, the statistical analysis of normality was performed through the Shapiro-Wilk statistic for each group, then the t-Student test was implemented. It was found that polydrugging adolescents have lower performance in the decision-making process, choosing the disadvantageous deck $A$ more frequently, while nonconsuming adolescents favored the advantageous deck $\mathrm{C}$. However, there was no significant difference in the choice of decks $B$ and $C$ between both groups The above shows that polydrug adolescents are more inclined to make impulsive and risky decisions than non-users. It is considered pertinent to carry out research to expand and support the results found.

Key words: Decision-making; Adolescents; Drugs consume. 


\section{Introducción}

El consumo de sustancias psicoactivas (SPA) es considerado uno de los problemas de salud pública a nivel mundial más alarmante en la actualidad (Oficina de las Naciones Unidas contra las drogas y el delito, 2018; Organización Mundial de la Salud, 2016). En Colombia, según el Estudio Nacional de Consumo de Sustancias Psicoactivas en Población Escolar - 2016, la edad promedio para el inicio de consumo es aproximadamente 14 y 15 años (Observatorio de Drogas de Colombia, Ministerio de Justicia y del Derecho, Ministerio de Educación Nacional, Ministerio de Salud y Protección social, Comisión Interamericana para el Control del Abuso de Drogas CICAD, 2016).

El fenómeno de la adicción requiere ser atendido desde investigaciones que permiten medir las conductas que se derivan del consumo, así como de realizar modelos que expliquen los procesos adictivos y las alteraciones neuropsicológicas que pueden estar asociadas. Se ha demostrado que las consecuencias derivadas del consumo de SPA tienen efectos significativos en el Sistema Nervioso Central (SNC) provocando deterioro cognitivo, disminución en el volumen de estructuras cerebrales y alteraciones en la toma de decisiones, como se puede determinar por medio de estudios con neuroimágenes (Merchán, 2014).

Uno de los procesos cognitivos afectados debido al consumo de SPA es la toma de decisiones, que se define como la capacidad de realizar una elección entre diferentes alternativas para resolver una situación y se considera que está guiada por factores emocionales, que apoyan la predicción y emisión de juicios teniendo en cuenta las consecuencias a corto y largo plazo de una elección (Chimbo, 2014; Márquez, Salguero, Paíno \& Alameda, 2013). Los adolescentes tienen mayor vulnerabilidad frente a la dificultad de toma de 
decisiones ya que son propensos a tomar decisiones poco ventajosas e impulsivas, por el desequilibrio en la maduración del Sistema de Control Cognitivo que se vincula a los procesos lógicos y de razonamiento (Acuña, Castillo, Bechara \& Godoy, 2013). La etapa de la adolescencia es crítica para la maduración cerebral, las estructuras y las funciones cerebrales se encuentran en constante desarrollo y los daños neurológicos que puedan derivarse del consumo de alguna droga pueden provocar déficits en las funciones cognitivas permanentemente (Nuño \& Flores, 2004).

En el proceso de maduración cerebral de la adolescencia, el desarrollo de los lóbulos frontales es crucial y se relaciona con comportamientos característicos de los adolescentes, como la búsqueda de independencia, el incremento de la necesidad de establecer relaciones sociales y afectivas, conductas impulsivas, riesgosas y novedosas, además de vincularse con las funciones ejecutivas (Gambara \& González, 2002).

A pesar de que los estudios acerca de las alteraciones provocadas por el consumo de SPA, no es clara la relación específica de los efectos en la toma de decisiones en adolescentes consumidores, se pretende comparar el rendimiento en el proceso de toma de decisiones de un grupo de adolescentes colombianos consumidores de sustancias psicoactivas con un grupo de adolescentes no consumidores con características sociodemográficas similares.

\section{Antecedentes teóricos y empíricos}

\section{Toma de decisiones}

En las últimas décadas se han realizado diferentes estudios en torno al proceso de toma de decisiones (Acuña, et al., 2013; Acuña, \& Rivera, 2009; 
Alameda-Bailén, Salguero-Alcañiz, Merchán \& Paíno-Quesada, 2014; Bechara, Damasio, \& Damasio, 2003; Bernal, Antonio, Arocena, \& Vicente, 2014; Bonilla, González, Bonilla, Muñoz, \& Baldovino, 2017; Broche, Herrera, \& Martínez, 2014; Calle, 2017; Gómez, 2006; Michelini, Acuña \& Godoy, 2016; Verdejo \& Pérez, 2006;). Este es un proceso mediante el que se realiza una elección entre varias alternativas para resolver determinada situación que se presenta en algún contexto (Chimbo, 2014). Por otra parte, este proceso se considera como una habilidad que permite al individuo determinar el curso de la acción más adaptativa frente a una serie de posibilidades conductuales, logrando realizar filtros para anticipar las consecuencias de una conducta (Márquez, et al., 2013).

Estos filtros se realizan por medio de dos tipos de juicios cognitivos, el subjetivo y el metacognitivo. Un juicio subjetivo tiene como función dar bases informativas para realizar acciones. Mientras que en el juicio metacognitivo la acción o decisión tomada se basa principalmente en el contenido de información evocada mediante la experiencia (Flores, 2006 como se citó en Pino \& Urrego, 2013). Otras posturas defienden que la toma de decisiones se encuentra guiada por procesos emocionales, ya que ayudan a predecir y emitir juicios, formar intenciones y planificar acciones (Sarmiento-Rivera \& RíosFlórez, 2017; Michelini, Acuña \& Godoy, 2016).

Damasio (1998) propone la hipótesis del marcador somático, que se refiere a un indicador del cambio fisiológico que refleja un estado emocional y cómo este interfiere en la toma de decisiones. El marcador somático es el resultado de la asociación de las respuestas emocionales de una elección y las consecuencias que tiene, ya sea positiva o negativa. De este modo, la 
aparición del marcador somático agiliza el proceso de toma de decisiones y de planificación necesario para realizar conductas sociales más adaptativas.

De acuerdo con esta hipótesis, las respuestas generadas por una emoción influyen en la ejecución de determinada acción comportamental, ya sea de evitación o aproximación; esto se debe a que el organismo presenta respuestas anticipatorias en la conductancia eléctrica de la piel cuando consideran que hay riesgo en una decisión, sin embargo, sujetos con lesiones prefrontales no presentan este tipo de respuesta (Sarmiento-Rivera \& Ríos-Flórez, 2017; Alcántara \& Molero, 2010).

Por otra parte, Rubiales, Urquijo, Said y Macbeth (2017) identifican diferentes tipos de toma de decisiones en relación con las consecuencias futuras. En primer lugar, la toma de decisiones bajo incertidumbre hace referencia a los momentos en los cuales no existen reglas claras para solucionar un problema y la persona no cuenta con información sobre los eventos que se puedan generar y en consecuencia no se puede asignar alguna probabilidad razonable, por lo que resuelve el problema basándose en sus sentimientos o intuición. Por otra parte, se encuentra la toma de decisiones bajo algún riesgo, en donde además de prever los posibles resultados, es posible asignar probabilidades ya que se tiene información explícita sobre las consecuencias y probabilidades de recompensas y castigos, por lo tanto, las decisiones se toman basadas en conocimientos sobre la situación y sus opciones.

A pesar de lo expuesto anteriormente, para que el proceso de toma de decisiones se realice diferentes estructuras cerebrales intervienen, dichas estructuras se han identificado por medio de Resonancia Magnética Funcional 
(fMRI), encontrando que la corteza dorsolateral izquierda y la corteza prefrontal ventral, se activan en tareas de comparación de costos y beneficios cuando se tiene que hacer alguna elección. Adicionalmente, con la fMRI se ha identificado que la toma de decisiones se vincula con dos sistemas, el sistema límbico y el sistema dopaminérgico-mesencefálico, los cuales se activan cuando hay una recompensa inmediata y en procesos de impulsividad, lo que apoya al cambio de decisión de una persona para obtener una respuesta más inmediata. Además, lesiones en la corteza orbitofrontal se relacionan con que las personas sean poco conscientes de sus decisiones simples o complejas (Flores \& Ostrosky, 2008).

Una de las investigaciones con fMRI que apoyan el postulado anterior, fue realizada por Hare (2010, como se citó en Murgich, 2017) encontró por medio de fMRI que el nivel de oxigenación de la sangre en la corteza prefrontal ventromedial se correlaciona con el valor de las recompensas en el momento de la toma de decisiones, sugiriendo un sistema de valoración durante el proceso de decisiones en esta región (Murgich, 2017).

Según Kentaro, Yoshi-Taka, Tomomi, Kenichi, Takeshi, Chisato, Kang, Kazuo \& Masato (2015) los eventos emocionales que se generan en el proceso decisorio influyen directamente en el curso de la acción de un individuo. Por lo tanto, la emoción es un modulador de la decisión. En su estudio con fMRI se midió la actividad neuronal durante la toma de decisiones, las imágenes encontradas muestran evidencia de que las decisiones placenteras generan activación en el cerebro medio donde se encuentran áreas como el giro fusiforme y el giro parahipocampal (Kentaro et al., 2015). 


\section{Mecanismos cerebrales en la toma de decisiones}

La toma de decisiones requiere redes extensas en diferentes áreas cerebrales; la corteza prefrontal juega un papel principal para el correcto procesamiento ejecutivo, atribuyendo a los lóbulos frontales la función de planificación, coordinación, monitorización del comportamiento y toma de decisiones (Bonet et al., 2015).

El lóbulo frontal es el más evolucionado filogenéticamente y el último en madurar ontogenéticamente, se encuentra situado en la parte central y anterior de la corteza cerebral y ocupa un tercio de esta (Calle, 2017; Herrera, 2007). Además, se compone por las regiones posteriores de la corteza frontal relacionadas con la actividad motora primaria, el área de asociación y por la corteza prefrontal que se divide en tres regiones orbitofrontal, dorsolateral y ventromedial (Ardila \& Ostrosky, 2008).

La corteza prefrontal tiene funciones asociadas con la memoria de trabajo, toma de decisiones, búsqueda de recompensas y está involucrada en la planificación de comportamientos adecuados o adaptativos de un individuo, por lo tanto, la actividad que se realiza en esta área está en función de la coordinación de pensamientos y acciones que se dirigen a una meta, lo que permite establecer juicios, predecir las consecuencias prospectivas de una acción, crear expectativas e inhibir comportamientos impulsivos (García, Tirapu, Luna, Ibáñez, \& Duque, 2010; Herrera, 2007; Jiménez \& Salcido, 2018; Valdéz \& Torrealba, 2005; Tirapu, García, Luna, Verdejo \& Ríos, 2012).

Como se mencionó anteriormente, la corteza prefrontal se divide en tres áreas, la primera de ellas es denominada como corteza orbitofrontal la cual se encuentra vinculada con procesos de toma de decisiones y compulsiones, 
también se relaciona con el procesamiento y regulación de emociones. En términos neuropsicológicos, un daño en esta área se asocia con la desinhibición conductual, cambios de personalidad, irritabilidad, distracción y conductas disruptivas o desadaptativas en un contexto (Ardila \& Ostrosky, 2008). También se relaciona con la dificultad para evaluar consecuencias o riesgos que se presentan en una decisión, ya que estas se toman bajo procesos de incertidumbre o riesgos.

La segunda área es la corteza dorsolateral, este circuito se considera el más importante de las funciones ejecutivas, su función está vinculada con procesos de organización o planificación de acciones, memoria de trabajo, flexibilidad mental, resolución de problemas y toma de decisiones. Es por esto, que los daños en esta área causan déficits en la capacidad para organizar información, cambiar acciones que se adapten a las demandas del contexto y elección de decisiones no riesgosas. También se presentan dificultades en la memoria de trabajo y retención de información, en el proceso de toma de decisiones los individuos se ven afectados ya que las elecciones que realizan suelen ser más desventajosas por fallas ejecutivas (Ardila \& Ostrosky, 2008; Chimbo, 2014; Sarmiento-Rivera \& Ríos- Flórez, 2017).

La tercera y última región es la corteza ventromedial, la cual orienta la motivación de acciones de un individuo, es decir se encuentra relacionada con el procesamiento de señales somáticas y emocionales que ayudan en la toma de decisiones hacia objetivos, también tiene funciones en los procesos de inhibición, detección y solución de conflictos (Bonet et al., 2015). Además, se relaciona con la valoración de consecuencias a largo plazo producto de una decisión, por lo que sujetos con lesiones en esta área presentan alteraciones 
en el procesamiento emocional y toma de decisiones, ya que no son sensibles a las consecuencias provocadas de una decisión y carecen de la capacidad de utilizar las emociones como guía conductual (Martínez, Sánchez, Bechara \&Román, 2006; Sarmiento-Rivera \& Ríos-Flórez, 2017).

Otra estructura que no se puede dejar de lado en el proceso de toma de decisiones es la amígdala cerebral, la ubicación de esta se encuentra en el lóbulo temporal medio, es vinculada con el procesamiento emocional y se relaciona con asociaciones de experiencias previas que pueden intervenir en la toma de decisiones. La amígdala permite que el cerebro detecte situaciones de peligro y que se produzcan respuestas eficaces para responder ante alguna situación, estas respuestas se encuentran mediadas por la consolidación de recuerdos (Martínez et al., 2006). Las lesiones en esta estructura se vinculan a la dificultad para la manifestación emocional y a la dificultad de experimentar respuesta en la conductancia eléctrica de la piel, la cual tiene como función ser un indicador para anticipar una decisión riesgosa (Manes \& Torralba, 2005).

El núcleo accumbens se encuentra ubicado en el núcleo caudado y la porción anterior del putamen, posee una gran concentración de neurotransmisores como la dopamina y los opiáceos. Por tanto, es responsable de la activación de los mecanismos de recompensa y de placer, los cuales obedecen a estímulos específicos y naturales como comida, bebida o sexo. La activación del mecanismo de recompensa implica que un individuo aprenda a responder ante hechos agradables o displacenteros, permitiendo que el curso de la acción frente a una decisión se base en los componentes aprendidos o previos (Murgich, 2017, Portellano, 2005). 
Los neurotransmisores son determinantes para el proceso de toma de decisiones, la dopamina, se produce en diversas áreas cerebrales, su función principal está asociada a la búsqueda de recompensas y placer, además es fundamental en el aprendizaje de nuevas conductas, su ejecución y el cambio conductual hacia una meta. Cuando este neurotransmisor se libera, facilita el aprendizaje útil para realizar elecciones adaptativas o ventajosas, esto tiene implicaciones en los estados motivacionales y en la toma de decisiones, actuando como señal ante la aparición de una recompensa (Malfaz \& Salichs, 2007; Ospina, Pérez, Vargas, Cervántes \& Rodríguez, 2017).

\section{Toma de decisiones en adolescentes}

La adolescencia es una de las etapas de transición del desarrollo humano y se encuentra en medio de la niñez y la adultez. Durante la adolescencia se generan diversos cambios físicos, cognitivos y sociales que permiten comprender y explicar las características que componen la conducta adolescente. Desde una perspectiva conductual, los adolescentes manifiestan la necesidad de búsqueda de independencia de las dinámicas familiares, además se afianzan las relaciones sociales con pares y se incrementa la búsqueda de situaciones novedosas y que implican algún riesgo. Tales conductas son necesarias ya que representan la base para el desarrollo de habilidades requeridas en la vida adulta y el logro de la autonomía (Acuña et al., 2013).

Uno de los cambios más importantes en esta etapa se vincula al desarrollo del Sistema Nervioso Central (SNC) estos intervienen en la modificación funcional, conductual y psicológica. Estos cambios ocurren especialmente en la corteza prefrontal y el hipocampo, dichas regiones se encuentran implicadas en 
la autorregulación, control de impulsos, procesos de aprendizaje y especialmente en el dominio de las funciones ejecutivas (Acuña et al., 2013).

La toma de decisiones en adolescentes depende de los cambios que ocurren en la maduración física, cognitiva y psicosocial que atraviesa un individuo (Flores, Castillo \& Jiménez, 2014; Gambara \& González, 2002). Es decir, las decisiones se encuentran mediadas por otros factores como la experiencia, la motivación y las consecuencias a largo plazo de las elecciones realizadas. En el caso de los adolescentes, a diferencia de los adultos, las decisiones se encuentran ligadas al componente motivacional (Broche \& Cruz, 2014; Gambara \& González, 2002; Vargas-Trujillo, Henao \& González, 2007).

También, se ha encontrado que las conductas riesgosas en adolescentes se asocian a deficiencias intelectuales, sin embargo, Steinberg, (2008) explica el proceso de toma de decisiones mediante el Modelo del Sistema Dual, en el cual se propone que existen dos sistemas de toma de decisiones: el primero de ellos es el Sistema Socioemocional, que se encuentra orientado a la búsqueda de recompensas, mientras el segundo se denomina el Sistema de Control Cognitivo, este sistema se vincula con los procesos de naturaleza lógica y racional. Durante la adolescencia estos sistemas no se encuentran en el mismo nivel de maduración, el Sistema Socioemocional se encuentra desarrollado, mientras que el Sistema de Control Cognitivo no lo está en su totalidad.

Ese desequilibrio conlleva a que los adolescentes realicen conductas riesgosas y a que las decisiones tomadas sean ineficientes, ya que los impulsos no pueden ser inhibidos por la región prefrontal (Bernal, et al., 2014; Faílde, Dapía, Alonso, \& Pazos, 2015). 
La toma de decisiones en adolescentes puede ser explicada desde otros modelos, uno de ellos es el denominado Modelo de desbalance del desarrollo cerebral (Casey, Getz, \& Galvan, 2008), este modelo, aunque es similar al anterior, plantea que la etapa de adolescencia se caracteriza por conductas riesgosas y de desempeño inferior en la toma de decisiones. Esto es explicado por una asincronía en el desarrollo de estructuras subcorticales y corticales del cerebro.

Las diferencias en la maduración provocan un periodo de vulnerabilidad incrementada, caracterizado por limitaciones para coordinar las emociones y la racionalidad (Broche \& Crúz, 2014). Lo anterior se puede evidenciar por medio de neuroimágenes (Casey et al., 2008; Leijenhorst, Gunther, Macks, Rombouts, Westenberg \& Crone, 2010; Steinberg, 2008), estas permiten hacer una correlación entre la búsqueda de sensaciones y los niveles de dopamina en los adolescentes. Este último aspecto, interviene en el circuito de recompensa, lo cual explica los cambios que se tienen asociados a la búsqueda de sensaciones y conductas de riesgo. La información acerca de los cambios que afectan la corteza prefrontal durante la adolescencia, determina que dicha zona no termina de madurar hasta llegar a la adultez temprana. También se evidencian cambios en el circuito mesolímbico que se relaciona con la búsqueda de recompensas y la motivación hacia una meta. Estos cambios en los circuitos neuronales provocan vulnerabilidad en los adolescentes ya que se incrementa la probabilidad de realizar conductas impulsivas y riesgosas (Bonilla et al., 2017; Broche-Pérez et al.,2015).

Por otra parte, el lóbulo frontal en los adolescentes aún está en una etapa madurativa, a raíz de esto los procesos de planificación y creación de 
estrategias presentan fallos, por lo cual la toma de decisiones frente a conductas como consumo de SPA, sexualidad, comportamientos antisociales y las dificultades para anticipar consecuencias, son más propensas en esta etapa (Acuña \& Rivera, 2009; Oliva \& Antolín, 2010). La capacidad para regular el comportamiento se encuentra ligada a la aparición de las operaciones lógicas formales que permiten a un individuo lograr un objetivo y solucionar problemas, el desarrollo inadecuado de estos procesos implica alteraciones en las funciones ejecutivas, lo que implica problemas en el desempeño conductual, social y cognoscitivo (Trujillo \& Pineda, 2008).

En adición a lo anterior, los cambios madurativos a nivel cerebral en la adolescencia no siguen un proceso lineal, por el contrario, varían según las zonas cerebrales. También se producen cambios neuroquímicos en los sistemas dopaminérgicos, glutamatérgicos y gabaérgicos. Los receptores de estos neurotransmisores van incrementando especialmente en la región prefrontal, siendo importantes en el sistema de recompensa y en el procesamiento de emociones. Por lo cual, un retraso en esta área afecta los procesos de aprendizaje, memoria, funciones ejecutivas y logra explicar la vulnerabilidad de los adolescentes a tomar decisiones riesgosas y buscar nuevas sensaciones. Lo anterior se asocia al consumo de drogas, conducta suicida, desórdenes emocionales y accidentes (Martínez, Fernández, La Torre \& Fernández, 2018).

La toma de decisiones acerca del inicio, mantenimiento o finalización de conductas de consumo está ligada a las representaciones sociales y es otro aspecto que se debe tener en cuenta en el caso de los adolescentes consumidores de SPA. Las conducciones del contexto familiar y social son 
determinantes para la toma de decisiones en los adolescentes, las representaciones sociales permiten que los grupos que componen una sociedad se comuniquen, logren entenderse y construyan explicaciones de la realidad en la que se encuentran, lo que permite orientar la toma de decisiones (Martos-Martínez, A., Molero-Jurado, M., Pérez-Fuentes, M., Gázquez Linarez, J \& Simón-Márquez, M. (2016); Nuño \& Flores, 2004). Este proceso es producto de razonamientos que vienen de sistemas de creencias, conocimiento, actitudes y prácticas.

Se han realizado estudios con respecto al consumo de SPA en adolescentes y su relación con la toma de decisiones, uno de estos fue realizado a 57 adolescentes consumidores de SPA, en el que se identificó que el $90 \%$ de los participantes tenían antecedentes familiares de consumo de SPA y las expectativas por parte de los adolescentes frente al consumo eran que "a ellos no les iba a pasar lo mismo" o "construir un mundo diferente". Por otra parte, dentro de los riesgos identificados se encontraron el ofrecimiento de drogas por parte de un amigo, invitación por parte de un vendedor y los ambientes de fiesta u ocio. A partir de las representaciones sociales y riesgos identificados, se logró establecer un modelo de toma de decisiones por parte de los adolescentes que se divide en tres momentos, el ingreso, la permanencia y la retirada del consumo de SPA (Broche-Pérez et al., 2015).

\section{Hipótesis del marcador somático en la toma de decisiones}

La hipótesis del marcador somático fue propuesta por Damasio (1998), para dar explicación a las alteraciones en la discriminación de información emocional. Esta hipótesis explica las decisiones como un proceso en el cual median las señales emocionales, este modelo explicativo integra los procesos 
cognitivos y emocionales con los sistemas neuroanatómicos, permitiendo una asociación entre las emociones con la capacidad de un individuo para decidir, teniendo en cuenta las consecuencias a largo plazo que genera un patrón conductual, en lugar de hacer una elección en función de las consecuencias inmediatas (Márquez et al., 2013; Melo, 2010).

Por otra parte, este modelo plantea que las dificultades de una persona para tomar decisiones ventajosas se atribuyen a deficiencias en los mecanismos emocionales que orientan la selección de una respuesta. Este mecanismo es el denominado marcador somático, que se define como "Las señales automáticas relacionadas con la emoción que se manifiestan por activación fisiológica como la conductancia de la piel, estas advierten a los sujetos antes de tomar decisiones riesgosas y los guían a tomar decisiones seguras" (Yip, Stein, Côté, \& Carney, 2019, p.1-2). La actividad eléctrica de la piel, también denominada conductancia de la piel es un tipo de medida psicofisiológica periférica, donde una sustancia conduce la corriente eléctrica. Las variaciones que presenta se deben a la secreción que tienen las glándulas sudoríparas que se encuentran distribuidas en la subdermis, ubicadas principalmente en las manos y en la planta de los pies (Londoño, 2017). Estas glándulas trabajan como resistencias eléctricas; cuando la resistencia disminuye, la conductividad aumenta y es cuando el sudor se impregna. La amplitud de esta respuesta eléctrica varía según la cantidad de secreción y de glándulas sudoríparas activadas (Londoño, 2017). La conductancia de la piel se ha estudiado en procesos que se relacionan con el comportamiento humano como la atención, ejecución de acciones, emociones y toma de decisiones debido a que depende del grado de activación del Sistema Nervioso Simpático. 
Requena, Requena, Merino y Carmona (2017), mencionan que los marcadores somáticos son sentimientos que se asocian al aprendizaje con resultados predecibles, lo que indica que estos actúan en el proceso de toma de decisiones a corto, mediano o largo plazo.

Los marcadores somáticos se generan a partir de la homeostasis y auto regulación, provocando cambios fisiológicos en el cuerpo y actuando como alarmas emocionales que establecen vínculos entre experiencias positivas o negativas pasadas con las decisiones antes de que estas se tomen. Estos eventos se pueden explicar a partir de dos procesos: los inductores primarios 0 los inductores secundarios. Los inductores primarios se dan de modo innato o por medio de aprendizaje de eventos placenteros o aversivos, por tanto, si alguno de estos estímulos se encuentra presente, se genera una respuesta emocional de manera automática. Por otra parte, los inductores secundarios son eventos que se generan a partir de recuerdos personales que pueden ser placenteros o aversivos (Bechara et al.,2003).

A nivel neuroanatómico, la corteza orbitofrontal es la estructura cerebral primordial para la producción de los marcadores somáticos por medio de los inductores secundarios, esto implica que las alteraciones en esta área limitan la capacidad de generar los marcadores somáticos más adaptativos para responder ante algún estímulo. Por otro lado, los estados somáticos son generados por la amígdala, esta estructura tiene la función de producir las señales emocionales y las respuestas conductuales que se generan ante un estímulo, ya sean de aproximación o de retirada. Arias, Rodríguez y García (2017) manifiestan que, frente a la toma de decisiones, los marcadores somáticos tienen una función primordial en la reducción de las posibles 
alternativas a elegir y en el rechazo de las opciones que producen emociones negativas.

Los marcadores somáticos interfieren en dos procesos de la toma de decisiones, el primero es cuando se genera un sentimiento y el segundo sirve como mediador en el curso de una acción frente a diversas opciones posibles. Al guiar el proceso de toma de decisiones, las señales somáticas influencian conductualmente los pensamientos o recuerdos, es decir, mientras un individuo procesa las opciones dadas por el contexto, los marcadores somáticos permiten la aceptación o el rechazo de una alternativa antes de que se realice la elección (Broché et al., 2014). Cuando las señales somáticas se asocian a los inductores primarios, en el cerebro se consolida el valor afectivo del estímulo. Por tanto, cuando estos estímulos se presenten posteriormente, los recuerdos evocados se convertirán en un inductor secundario, generando la reactivación de los estados somáticos de un inductor primario. En otras palabras, si el marcador somático se produce ante una decisión o evento negativo, la conducta se orientará hacia la evitación de determinada situación, por el contrario, si se produce ante una decisión o evento placentero se buscará la aproximación de la situación (Márquez et al., 2013).

Las señales emocionales experimentadas a partir de los eventos pasados que se asocian a una situación actual, por lo tanto, un individuo se predispone a la decisión que se tomará. En este caso, los marcadores somáticos integran la información y cambios que se producen a nivel visceral y muscular, funcionando como un indicador de las representaciones mentales que se asocian a la decisión. Lo anterior es de gran importancia en situaciones complejas o de incertidumbre, ya que se atiende a los valores emocionales de 
las situaciones para poder tomar una decisión (Broche \& Cruz, 2014). A partir de lo anterior, la toma de decisiones es producto de las dimensiones racionales que consideran el costo o beneficio de una alternativa $y$, las señales emocionales de las recompensas o castigos de una decisión.

La importancia de los marcadores somáticos se puede atribuir a diversas características. Inicialmente, la intensidad de la atención sobre el resultado negativo al que puede conducir una acción determinada. En segundo lugar, la señal de alarma provocada en el individuo, que puede llevar a rechazar el curso de la acción, permitiendo que se elija entre otras alternativas. Finalmente, el aumento de la precisión y eficiencia del proceso de elección (RegalDomínguez, García de Vinuesa, Aguayo-González, Luque-Sendra, \& GonzálezRegalado Montero, 2017). Los marcadores somáticos son un soporte teórico para las bases neurofisiológicas de la retroalimentación y para la especificidad de la actividad pronostica en diferentes grupos clínicos. Esto no niega la importancia de los marcadores somáticos que señalan éxito o fracaso, pero en cambio resalta la irreductibilidad de la toma de decisiones a los marcadores somáticos que se ubican en los niveles de "vértice" de la regulación de la actividad anticipatoria y que, en cambio, están modulados por los rasgos de la personalidad. Los niveles de "vértice" son la aceptación positiva de condiciones inciertas y la aversión a la incertidumbre combinada con la confianza en hechos conocidos en la búsqueda de claridad (Kornilova, Chumakova \& Kornilov, 2018).

Damasio y Tranel, (2005) (como se citó en Londoño 2017) comenzaron evaluando las respuestas del Sistema Nervioso Autónomo por medio de la conductancia dérmica. En su estudio, participaron sujetos experimentales con 
lesiones en el sector ventromedial del lóbulo prefrontal y sujetos sin ninguna condición médica, a estímulos sorpresivos y detectar la conductancia de la piel (Londoño, 2017). Además construyeron diversos experimentos de juego para intentar validar la hipótesis del marcador somático; finalmente propusieron una manera de testear la función neuropsicológica de la toma de decisiones mediante el lowa GamblingTask (IGT), que es una tarea de toma de decisiones que parte de la hipótesis de los marcadores somáticos, situando al sujeto en la necesidad de elegir entre cuatro mazos de cartas, buscando reflejar condiciones similares de la vida cotidiana en la toma de decisiones (Bonilla et al.,2017).

En Colombia se realizó un estudio por Bonilla-Santos et al., (2017) previamente indican que "la hipótesis del marcador somático establece que las emociones participan del proceso cognitivo de la toma de decisiones guiando la conducta y dotando a la experiencia de una cualidad positiva o negativa que permite la adaptación del individuo al medio social" (p.15); y plantearon como objetivo evaluar la toma de decisiones mediante el desempeño en la tarea lowa Gambling Task (IGT) en niños y niñas que cumplían con uno o dos criterios según el DSM-IV para desarrollar el Trastorno Disocial de la Conducta (TDC); el análisis estadístico se hizo mediante análisis descriptivos de la ejecución de los participantes en los ensayos del IGT con el fin de obtener las puntuaciones totales. Los resultados mostraron diferencias estadísticamente significativas entre el grupo estudio y de control para la selección de los mazos de cartas desventajosas durante la ejecución de la tarea. Los niños en riesgo presentaron un desempeño menor para la prueba general de toma de decisiones. 
En otro estudio se buscó identificar el rendimiento de pacientes drogodependientes en una tarea neuropsicológica sensible a alteraciones en la toma de decisiones teniendo en cuenta la hipótesis del marcador somático. Verdejo \& Pérez, (2006), utilizaron una muestra de 106 pacientes consumidores de diversas SPA que se encontraban en fase de deshabituación y que habían superado la fase de desintoxicación, a quienes se les aplicó la versión computarizada del IGT, los resultados obtenidos arrojaron un deterioro significativo en la toma de decisiones y no se encuentra relevancia clínica por el tipo de sustancia consumida o el tiempo de abstinencia.

Salvador et al., (2010), realizaron un estudio acerca de la toma de decisiones con una variación del IGT, con el objetivo de evaluar la toma de decisiones con la intención de atenuar la penetrabilidad cognitiva que se encontró en el estudio y teoría original. Para este estudio se trabajó con 14 sujetos entre los 22 y 33 años. Al igual que en el IGT cada participante debía elegir entre cuatro mazos de cartas, estos se les presentaban de 2 en 2 durante 4 bloques de 30 ensayos cada uno. En la variación, los participantes debían pasar por tres fases diferentes, inicialmente debían leer una serie de instrucciones para entender la metodología y dinámica de la tarea a realizar. En la segunda, se realizaron ensayos para saber si se habían comprendido las instrucciones y finalmente, pasaron por los cuatro bloques de 30 elecciones consecutivas. Para el estudio de toma de decisiones se tomaron en cuenta tres variables: número y tipo de elecciones, valoración de las opciones y tiempo de respuesta.

La discriminación de las opciones buenas y malas fueron contrastados con el trabajo de Bechara, Damasco, Tranel y Damasio, (1997) debido a que no se 
les informó del monto total de dinero que acumulaban al realizar alguna elección. En adición, los resultados indican que la valoración que se le da a las opciones con beneficios a largo plazo no se evidencia hasta el último bloque. Teniendo en cuenta los tiempos de reacción, se confirma la teoría del marcador somático, al determinar que una mayor activación emocional genera una mayor latencia de respuesta para las opciones buenas frente a las malas que generan una menor activación.

Las variaciones que se implementaron dificultan en mayor medida la toma de decisiones lo que involucra con más eficacia la corteza prefrontal. Sin embargo, debido al número de la muestra empleada los resultados presentan limitaciones para la generalización e interpretación de los resultados (Bechara et al., 1997).

Mogedas y Alameda (2011) realizaron un estudio con el fin de determinar la influencia de los marcadores somáticos sobre la toma de decisiones, la muestra estaba conformada por 66 personas divididos en dos grupos compuestos por 33 drogodependientes y 33 personas del grupo de control. Para la investigación realizaron una entrevista semiestructurada sobre variables sociodemográficas y dos versiones del lowa Gambling Task, entre estas la computarizada. Los resultados mostraron diferencias significativas entre el grupo control y experimental en la ejecución de la tarea. El 75,76\% de los pacientes drogodependientes presentaron deterioro en la ejecución de la tarea frente a un $24,24 \%$ que la realizan de forma adecuada, esto indica la presencia de alteraciones en los procesos de toma de decisiones en pacientes consumidores de SPA, teniendo menor rendimiento que el grupo control. Lo 
anterior, posiblemente se debe a una dificultad para generar estados somáticos en función de las posibles consecuencias futuras.

\section{Sustancias Psicoactivas y mecanismos neuroquímicos}

El consumo de sustancias psicoactivas es considerado como uno de los problemas de salud pública más grandes a nivel mundial (OMS, 2016). El Manual Diagnóstico y Estadístico de los Trastornos Mentales (DSM-V) clasifica diez clases diferentes de sustancias o drogas, como alcohol, cafeína, cannabis, alucinógenos, inhalantes, opiáceos, sedantes, hipnóticos y ansiolíticos, estimulantes, tabaco y otras sustancias. Cada una de estas producen efectos y mecanismos de activación diferentes (Asociación Americana de Psiquiatría (APA), 2014; Guerra, 2011) y su consumo genera un sistema de recompensa cerebral, provocando sensaciones de placer que refuerzan el comportamiento de consumo.

Por otra parte, en Colombia, de acuerdo con el Estudio Nacional de Consumo de Sustancias Psicoactivas en población escolar (Obsevarorio de Drogas de Colombia et al.,2016), realizado a 3.243.377 estudiantes entre $7^{0} \mathrm{y}$ $11^{0}$, con edades entre los 12 y 18 años, la edad promedio de inicio de consumo se encuentra entre los 14 y 15 años. Las sustancias de mayor consumo son el tabaco con una prevalencia del $28,3 \%$ en hombres y del $21,2 \%$ en mujeres; alcohol con $37,9 \%$ en mujeres y $36,1 \%$ en hombres; marihuana indicando que el $13,1 \%$ de los varones y el $10,5 \%$ de las mujeres han consumido alguna vez esta sustancia; cocaína con el 4,8\% en hombres y el 3,1\% en mujeres; éxtasis con una diferencia significativa entre hombres y mujeres con el $2,4 \%$ y $1,9 \%$ respectivamente (Observatorio de Drogas de Colombia et al., 2016). 
El consumo de SPA afecta neurológicamente al consumidor, el grado de afección depende de factores como el uso, abuso y dependencia a una sustancia. El uso de una droga se refiere al consumo ocasional y episódico de una sustancia, sin que este genere tolerancia, abstinencia o consecuencias negativas derivadas del mismo (Becoña \& Cortés, 2010; Volkow, 2014).

Por otra parte, el abuso se define como cualquier consumo que dañe el bienestar físico, mental y social del individuo por el uso continuo de la sustancia y la dependencia consiste en el uso excesivo de esta, adquiriendo la máxima prioridad para el individuo, por lo cual, desencadena una serie de síntomas negativos a nivel cognitivo, conductual y fisiológico, esto se relaciona con la falta de control y un carácter compulsivo que de acuerdo con los estudios se encuentra vinculada con factores de vulnerabilidad que afectan las funciones ejecutivas, el comportamiento y los estados emocionales debido a alteraciones cerebrales en el sistema neurobiológico (Acosta, Cuartas, \& Juárez, 2017; Acosta, Juárez \& Cuartas, 2018; Camelo, Olivares, \& Carballeira, 2016; OMS, 2004)

En la conducta adictiva intervienen diversas zonas cerebrales y daños en estas áreas dificultan la realización de tareas, los procesos cognoscitivos y aumentan el comportamiento impulsivo (Beverido, 2010; Villa, Navarro \& Villaseñor, 2017). Una de estas estructuras es el núcleo accumbens cuya función permite explicar la conducta adictiva. Teniendo en cuenta lo anterior, la neurobiología del consumo está guiada por el circuito de recompensa y la dopamina como neurotransmisor implicado (Arias, 2005; Mantero, 2018; Próspero, 2014). El circuito de recompensa es un sistema primitivo y su activación facilita el aprendizaje y el mantenimiento de unas conductas que 
proporcionan placer en un individuo, está conformado por estructuras del cerebro medio como el Área Tegmental Ventral (ATV), la sustancia negra y el cerebro anterior (amígdala, tálamo, hipocampo, corteza cingulada y prefrontal); este circuito juega un papel primordial en el desarrollo de la dependencia a alguna sustancia y de este depende el mantenimiento del consumo y recaídas (Becoña \& Cortés, 2010; Juárez, 2019).

El incremento de dopamina provocado por el consumo de SPA activa el circuito de recompensa intensificando la sensación de placer provocando que el sujeto vuelva a consumir posteriormente (Corominas, Roncero, Bruguera \& Casas, 2007). Cuando se presenta un consumo crónico de SPA, se produce un efecto de tolerancia por lo cual se necesita consumir una mayor cantidad de esta para lograr el mismo grado de estimulación, ya que al consumir en la misma proporción no se obtiene el mismo efecto (Bahena, Flores \& Arias, 2000).

La dependencia a sustancias psicoactivas genera activación de los mecanismos motivacionales dentro del cerebro, que normalmente se activan por estímulos necesarios para la supervivencia. En este caso, las sustancias engañan al cerebro llevándolo a responder como si estas fueran necesarias biológicamente (Méndez, Romero, Cortés, Ruíz \& Próspero, 2016). A medida que el consumo se hace más frecuente, las sustancias psicoactivas y los estímulos que se asocian al consumo adquieren mayor importancia, lo que se conoce como sensibilización al incentivo (Sanz, 1996; Villalba \& Verdejo, 2012). El aprendizaje asociativo activa los procesos motivacionales para la conducta adictiva, es por esto por lo que los estímulos que se asocian a esta conducta tales como personas, objetos o lugares pueden provocar recaídas 
incluso si se tiene un periodo largo de abstinencia (OMS, 2002 como se citó en OMS, 2005).

Modelos Neuropsicológicos de la adicción implicaciones en la toma de decisiones

Existen diferentes modelos que explican los procesos y cambios neuropsicológicos y neuroanatómicos que se producen en la motivación, emociones, conducta y en los procesos cognitivos. Estos cambios pueden asociarse a que la conducta adictiva se mantenga y en consecuencia se alteren capacidades de inhibición de respuesta, planificación y toma de decisiones (Merchán, 2014).

En consumidores de SPA se evidencia que los procesos con un deterioro más prolongado son las funciones ejecutivas, es por esta razón que se mantienen conductas desadaptativas. Los modelos que se describen a continuación pretenden explicar cómo la conducta adictiva interfiere en el control inhibitorio, compulsiones y déficits en toma de decisiones (Chimbo, 2014).

\section{Modelo basado en la sensibilización de los mecanismos motivacionales}

Este modelo propuesto por Robinson y Berridge (2008) se basan en la premisa de que el consumo de SPA produce nuevas adaptaciones neuronales que atribuyen cargas motivacionales a los estímulos que se encuentran presentes en el entorno. Lo anterior explica la razón del mantenimiento de consumo aun cuando alguna sustancia ya ha perdido efectos placenteros, debido a que tales estímulos determinan el curso de una acción hacia una meta. En este caso, la toma de decisiones acerca del reiterado consumo se debe a los efectos motivacionales que se desencadenan por las variables 
ambientales asociadas al hábito de consumo, que pueden aparecer implícitamente por medio de activación psicofisiológica o por pensamientos, o explícitamente mediante la sensación de deseo de consumo (Merchán, 2014).

Modelo de daño en la atribución de relevancia y la inhibición de respuesta

Este modelo complementa las explicaciones sobre el consumo inicial, compulsiones en el consumo y recaídas en el periodo de abstinencia. La explicación dada por este modelo parte de que a las sustancias psicoactivas y los efectos placenteros de su consumo se les atribuye una propiedad reforzante, que activa el sistema de recompensa en una proporción mayor que a los reforzadores naturales, los cuales pierden relevancia motivacional. Además, los procesos inhibitorios que apoyan la toma de decisiones cuya función es impedir conductas inapropiadas son ineficientes por la relevancia motivacional derivada del consumo, por lo tanto, las elecciones que se realizan son funcionalmente menos adaptativas (Ruiz, 2011).

\section{Modelos basados en la transición entre impulsividad y compulsión}

Este modelo propone que los efectos reforzantes de la conducta adictiva pasan de ser actos impulsivos a rituales compulsivos. Esto provoca que este patrón de comportamiento se vuelva automático e inflexible, sin que se tengan en cuenta las consecuencias nocivas derivadas de la decisión tomada. Esta transición de la impulsividad a la compulsión se explica por un desplazamiento del control en la corteza prefrontal hacia los ganglios basales, núcleo accumbens y el núcleo estriado dorsal (Merchán, 2014).

Modelo de vulnerabilidades en los procesos de decisión

Este modelo integra aspectos de otros que se enfatizan en las dificultades de los procesos de toma de decisiones, partiendo de la premisa de que el 
consumo provoca neuro adaptaciones en los sistemas de planificación, hábitos y reconocimiento situacionales. Estos sistemas se encargan de modular las respuestas y elecciones frente a un contexto. Cuando se producen decisiones inadecuadas algunos factores de vulnerabilidad están presentes como la desestabilización motivacional, señales de euforia ante alguna recompensa, fallos en el sistema de búsqueda, distorsiones cognitivas y alteraciones en el aprendizaje que asocian estímulos falsos a un evento (Merchán, 2014).

\section{Modelo de alteraciones en la toma de decisiones (marcadores somáticos)}

Este modelo establece que las adicciones se deben a la dificultad en la toma de decisiones, asociadas a mecanismos motivacionales y emocionales en la elección de una respuesta (Verdejo \& Bechara, 2009, Verdejo \& Bechara, 2010). La inhabilidad emocional conlleva a tomar malas decisiones en la vida cotidiana de una persona, es decir, que las decisiones no dependen únicamente de procesos racionales, sino que dependen de las emociones (Arteaga \& Quebradas, 2010). Cuando se produce una reacción emocional y se experimenta como si la situación estuviera sucediendo, se emiten una serie de señales corporales o marcadores somáticos (Márquez et al., 2013). Los marcadores somáticos son los que regulan y determinan la adecuada ejecución y elección de una decisión en situaciones complejas, ya que organizan y evalúan las consecuencias en un periodo corto de tiempo. En el caso de los consumidores de SPA, los marcadores somáticos no funcionan adecuadamente, ya que las señales emocionales están ligadas con el consumo. Por esta razón, estas personas buscan un refuerzo inmediato sin evaluar los costos, lo que implica que la producción de aprendizaje nuevo de las experiencias se limite (Acosta et al., 2011). 


\section{Toma de decisiones y consumo de sustancias psicoactivas}

El consumo de SPA se relaciona con la alteración de diferentes procesos neurológicos y psicológicos, las personas consumidoras de SPA presentan dificultades en la capacidad de tomar decisiones, esto se refleja en que las elecciones que estas realizan son desadaptativas y no son aceptadas socialmente en diferentes áreas. Lo anterior, puede estar relacionado con la valoración emocional inapropiada, sesgada y excesiva de las recompensas asociadas a alguna alternativa y por subestimar las consecuencias negativas de esta (Verdejo, 2006).

Por otra parte, el patrón conductual de los individuos consumidores es caracterizado por la tendencia a actuar basados en las recompensas inmediatas a pesar de que las consecuencias a un periodo de tiempo determinado sean negativas lo cual se denomina "miopía hacia el futuro" (Mogedas-Valladares \& Alameda-Bailén 2011). Este fenómeno se explica por medio de la hipótesis del marcador somático que a pesar de que fue propuesto para explicar los mecanismos cerebrales de pacientes con lesiones orbitofrontales, también es útil para explicar los problemas en toma de decisiones asociado al consumo de SPA (Mogedas \& Alameda, 2011). El modelo del marcador somático afirma que las dificultades en la toma de decisiones ventajosas en consumidores se derivan de la falta o deficiencias en los mecanismos emocionales que permiten al individuo anticipar las respuestas y los resultados derivados de una elección. Dichos mecanismos emocionales son provocados por procesos de homeostasis y autorregulación (Gómez, 2006; Regal, De las Heras, Aguayo, Luque \& González, 2017; Sanz,1996). 
Otros autores proponen que los marcadores somáticos son producidos por los inductores primarios y los secundarios (Alameda-Bailén et al., 2014; Castrillón, 2018). Los inductores primarios son aquellos estímulos que se han asociado a algún evento placentero o aversivo, por lo cual si alguno de estos estímulos se encuentra presente en alguna situación automáticamente provocará una respuesta emocional (Alameda et al., 2014; Castrillón, 2018). Mientras que los inductores secundarios son aquellos eventos que se derivan de la experiencia emocional o de los recuerdos personales de un individuo. En el caso de los consumidores, la presencia de un inductor primario o secundario facilita la generación de un evento emocional (Verdejo, 2006).

La estructura cerebral asociada y crucial para explicar anatómicamente el funcionamiento de los inductores primarios es la amígdala. Dicha estructura tiene la función de activar las señales emocionales y de integrar a estas señales conductas de aproximación o evitación (Arteaga \& Quebradas, 2010). Cuando las señales emocionales son experimentadas se asocian a un evento, consolidando el valor afectivo ante el evento o estímulo, permitiendo que el recuerdo o reexperimentación del evento sea importante en la vida del individuo (Alcántara \& Molero, 2010). En consumidores, las señales emocionales emitidas son desproporcionadas con relación a los recuerdos o experiencias de consumo vividas. Sin embargo, la valoración emocional de un consumidor de SPA frente a una sustancia puede ser positiva o motivante al desear o tener impulsos de consumir la droga, o emocionalmente desagradable por los efectos experimentados una vez es consumida, esto se denomina disociación entre la valoración afectiva y el valor incentivo del estímulo, y puede 
potenciar o debilitar el curso de las acciones y elecciones de una persona (Verdejo, 2006).

Teniendo en cuenta que la toma de decisiones es un proceso guiado por las emociones, los consumidores presentan una característica en común que es la dificultad e incapacidad de tomar decisiones adaptativas (Alameda, Quesada, \& Mogedas, 2012). Un claro ejemplo de esto es la compulsión de consumir determinada sustancia a expensas de alternativas mucho más reforzantes a mediano y largo plazo. Esto implica que a menudo se realicen conductas impulsivas que afectan la vida cotidiana, como inversiones riesgosas, discusiones frecuentes con personas cercanas y tener antecedentes penales por realizar conductas delictivas (Alameda et al., 2012).

Verdejo-García, Aguilar de Arcos y Pérez-García (2004) refieren que el consumo prolongado de diferentes sustancias psicoactivas se asocia al deterioro de funciones neuropsicológicas, en especial las funciones ejecutivas. En su investigación, cuyo objetivo fue examinar la relación entre la gravedad del consumo de SPA sobre los procesos ejecutivos de fluidez, memoria de trabajo, inhibición de respuestas y toma de decisiones se encontró una gran relación entre el deterioro ejecutivo y además estas alteraciones tienen repercusiones negativas en la eficacia de los tratamientos.

Se desconoce la causa exacta de las alteraciones provocadas por el consumo de SPA en la toma de decisiones, sin embargo, la evidencia muestra que, al presentar alteraciones en el área orbitofrontal de la corteza prefrontal, la interpretación de la información social y emocional produce cambios en la personalidad, de lo cual resulta la dificultad para entender y seguir normas sociales, procesar emociones y las consecuencias de las decisiones (Mariño, 
Castro \& Torrado, 2012). A partir de esto, se ha demostrado que los consumidores presentan alteraciones al generar los marcadores somáticos que se encuentran asociados a la toma de decisiones, esto implica que las consecuencias no se evalúen y puedan desencadenarse resultados negativos (Mariño et al., 2012).

El proceso de toma de decisiones en consumidores es influenciado por la valoración emocional excesiva a las recompensas inmediatas y por la infraestimación a las consecuencias que se derivan de una elección (Verdejo \& Bechara, 2009) lo cual refleja la incapacidad para anticipar las consecuencias prospectivas de las conductas que realizan en la cotidianidad. En adición, también presentan grandes dificultades en el reconocimiento y percepción emocional, evidenciándose en bajos niveles de empatía y reciprocidad emocional ante estímulos agradables y desagradables, y en una sobrestimación en el control de las emociones en respuesta ante algún estímulo (Mogedas \& Alameda, 2011). Lo anterior se relaciona con los déficits motivacionales que provocan una preferencia por los efectos reforzantes de una sustancia y la pérdida de reforzadores naturales.

\section{La toma de decisiones y el lowa Gambling Task (IGT)}

El lowa Gambling Task (IGT) es una tarea utilizada que simula un juego de cartas en el que puede haber recompensa o castigo económico (Bechara, Damasio \& Damasio, 2003, como se citó en Broche-Pérez et al.,2015), la prueba se compone de cuatro barajas de cartas (A, B, C y D) con 60 cartas cada una de ellas, de las cuales la persona debe seleccionar cartas durante 100 ensayos con el objetivo de maximizar la recompensa o evitar perder dinero, en la selección de las cartas puede obtener recompensa o castigo, 
teniendo en cuenta que las barajas A y B producen mayores castigos a diferencia de las barajas $C$ y $D$ en las que hay mayor recompensa, lo cual el participante desconoce (Márquez et al., 2013; Ochoa, 2013)

EI IGT fue diseñado para evaluar la toma de decisiones en situaciones inciertas que implican riesgo y ambigüedad, de igual manera pretende comprobar la teoría del marcador somático y se construye para poder evaluar pacientes con lesiones prefrontales-ventro-mediales (PFVM) y lesiones bilaterales de las amígdalas cerebrales (Bechara, Damasio, \& Damasio, 2003; Bechara, Damasio, Damasio, \& Lee, 1999, como se citaron en Squillace, Picón, \& Schmidt, 2015). Se encuentra que en personar normales se llega a modificar el valor afectivo de acuerdo a su experiencia en el juego, lo que permite el desarrollo de señales emocionales (marcadores somáticos) que genera que el participante pueda anticipar las consecuencias en su toma de decisión, a diferencia de participantes que presentan lesiones como las mencionadas anteriormente, en los cuales se evidencia una dificultad para generar señales emocionales de acuerdo a sus sentimientos, por lo cual hay afectación en la anticipación de las consecuencias ya sea refuerzo o castigo dentro de su toma de decisiones de acuerdo a la elección o experiencia anterior (Márquez et al., 2013).

De acuerdo con la teoría de los marcadores somáticos, la respuesta emocional tiene gran influencia en la anticipación de consecuencias para la toma de decisiones como se muestra en la prueba de lowa Gambling Task (Bechara, Damasio, Damasio \& Anderson, 1994, como se citaron en Gordillo et al., 2010). Se entiende que la emoción en la toma de decisiones se refleja como una marca somática que antecede el factor cognitivo en la toma de 
decisiones (Damasio, 1994, como se citó en Gordillo, Araña, Salvador \& Mestas, 2011). De igual manera, se menciona que la amígdala sería la encargada de generar las señales emocionales a nivel del hipotálamo, núcleos del tronco cerebral y estructuras encefálicas, los cuales regulan las respuestas somáticas generando respuestas a nivel emocional, logrando anticipar diversas situaciones como agradables o desagradables de acuerdo con las consecuencias de estas, ya sea un refuerzo o castigo (García-Molina, Rodríguez, Vendrell, Junqué, \& Roig-Rovira, 2008).

Mediante la prueba de lowa Gambling Task, se ha comprobado que en personas que presentan lesiones en la corteza orbitofrontal tiene una inclinación por la selección de barajas en las que hay mayor castigo a diferencia de personas normales (Bechara et al., 1994,1999; Bechara et al., 1997 como se citaron en Kumar, Kumar, \& Benegal, 2019).

Sin embargo, en otros estudios existen incongruencias en los resultados que plantea la prueba, ya que también se ha evidenciado que en personas normales también había una tendencia a seleccionar cubiertas que ocasionaban mayor castigo principalmente del grupo B, a pesar de la experiencia obtenida (Adinoff et al., 2003, como se citaron en Kumar et al., 2019; Bechara \& Damasio, 2002; Crone \& van Der Molen, 2004).

Para evaluar la toma de decisiones se ha utilizado la prueba lowa Gambling Task (IGT) (Bechara, Damasio, Tranel \& Damasio, 2005, como se citaron en Dante, 2006) imitando las situaciones en que se debe hacer una elección en la vida real, con factores como la incertidumbre, la recompensa y el castigo (Moussa et al., 2014). También, es utilizada para medir el deterioro en la toma de decisiones relacionada con la corteza prefrontal ventromedial. Esta 
prueba permite identificar la habilidad de un sujeto para renunciar a recompensas inmediatas y obtener beneficios más altos a largo plazo (Gordillo et al., 2011).

La interpretación del IGT permite identificar no solo aspectos implicados en el proceso de la toma de decisiones, sino también con la memoria de trabajo, de acuerdo con Bechara (2004) las personas con una memoria de trabajo normal logran tomar buenas o malas decisiones, lo cual refleja que estos procesos son independientes. Otro aspecto que debe tomarse en cuenta para la interpretación de resultados es la existencia o no de un trastorno neurológico o psiquiátrico, aunque la evidencia tras la aplicación de la prueba indica que esta no evalúa algún trastorno específico, debido a que la población sin lesiones prefrontales realiza malas elecciones, similares a aquellos que sí las presentan.

EI IGT presenta algunas limitaciones en la credibilidad para determinar las deficiencias estructurales o funcionales de la corteza prefrontal, esta limitación se debe a la variabilidad dentro de los grupos clínicos, además se deben tener en cuenta variables como la hipersensibilidad a la recompensa o insensibilidad al castigo (Gordillo et al., 2011). Para probar esto, González, Ponce, Díaz y Marino (2010) realizaron una investigación en la cual aplicaron el IGT; no encontraron diferencias significativas en cuanto al sexo o nivel educativo de los participantes durante la ejecución de la tarea. En las edades se empieza a evidenciar diferencias a partir de los 56 años ya que el desempeño se ve disminuido.

Para evaluar estas variables Gordillo et al. (2011) realizaron una medición con una variante del IGT, en esta tarea la elección de dos mazos de cartas 
venía acompañada de penalizaciones altas e inmediatas, además de una alta ganancia a largo plazo. Mientras los otros dos mazos tenían una penalización baja inmediata con una menor ganancia a largo plazo. La hipótesis al realizar esta variación es que en la preferencia por los mazos con altas penalizaciones podría estar reflejada la insensibilidad al castigo y la preferencia por los mazos con alta ganancia a largo plazo junto con activación fisiológica se puede deber a la hipersensibilidad ante la recompensa. Además, la elección por los mazos con bajas penalizaciones podría implicar una dificultad para anticipar eventos.

Dentro de los resultados encontrados, se evidenció que, en ambas versiones, la original y la variante, los participantes preferían los mazos malos, lo que refleja la incapacidad para anticipar respuestas y consecuencias futuras, por lo que las elecciones se basan en las consecuencias o contingencias inmediatas (Gordillo et al., 2011). Además, en la versión original, Bechara et al. (1994) determinaron que los pacientes con lesiones en la corteza prefrontal ventromedial seleccionan más los mazos de cartas riesgosos en comparación con el grupo de control los cuales cambiaban de elección a medida que el juego avanzaba por los mazos ventajosos.

\section{Justificación}

El consumo de sustancias psicoactivas representa uno de los principales problemas de salud pública (Scoppetta, 2015), se estima que 3 de cada 15 jóvenes han consumido alguna sustancia psicoactiva por lo menos una vez (Hernández, Font \& Gras, 2015 citados en Trilloz-Vélez, Tamayo-Barragán \&Artunduaga-Molina, 2020). Dada su complejidad, este problema se ha estudiado a través de diferentes líneas investigativas y se han formulado 
modelos explicativos de la adicción como los factores biológicos, motivacionales y personalidad.

Aunque dichos modelos son de gran importancia, en los últimos años los estudios en neurociencias y los realizados a través de neuroimágenes, rescatan la relevancia de investigar sobre las alteraciones cognitivas que se asocian al consumo de sustancias psicoactivas, evidenciando una creciente necesidad de conocer y establecer correlatos neuropsicológicos del consumo de diferentes sustancias psicoactivas como la toma de decisiones (Merchán, 2014).

La toma de decisiones es considerada como el proceso mediante el cual un individuo realiza una elección frente a varias alternativas posibles. Este mecanismo permite realizar filtros, anticipar consecuencias a corto, mediano y largo plazo, logrando controlar y dirigir la conducta de una persona (Ardila \& Rosselli, 2007). Este proceso, puede verse alterado por factores emocionales, alteraciones neurológicas, consumo de SPA, entre otros factores. Se ha demostrado que el consumo simultáneo de varias sustancias psicoactivas se asocia con dificultades en la toma de decisiones, por lo cual las elecciones que hace una persona consumidora son ineficientes, desadaptativas, impulsivas y riesgosas (Verdejo, 2006). Estas conductas impulsivas y riesgosas pueden compararse con el proceso de toma de decisiones en los adolescentes debido a la falta de madurez en el sistema de control cognitivo, por lo tanto, los impulsos no pueden ser inhibidos por la región prefrontal del cerebro y las elecciones se realizan basados en procesos emocionales (Faílde et al., 2015).

En el caso de adolescentes consumidores la dificultad en la toma de decisiones es aún mayor, ya que tienen un índice de vulnerabilidad 
incrementada, es decir, los componentes biológicos a nivel de maduración cerebral y las alteraciones derivadas del consumo de sustancias los limitan en mayor medida a coordinar las emociones y la racionalidad, por lo cual no son eficientes para evaluar los riesgos a largo plazo en determinada situación, basándose en las recompensas inmediatas de algún evento (Broche, 2015).

La evidencia muestra que existen alteraciones neuropsicológicas que repercuten en la toma de decisiones en consumidores de SPA, y en los adolescentes el rendimiento en este proceso se ve alterado aún más por los procesos de maduración cerebral de los lóbulos prefrontales característicos en esta etapa, provocando mayor vulnerabilidad relacionada con la toma de decisiones riesgosa e impulsiva (Gambara \& González, 2002).

Partiendo de lo anterior, se han realizado diferentes estudios para determinar el perfil neuropsicológico de los consumidores de SPA (Marino \& Julián, 2010), en especial para evaluar el grado de afección en los procesos cognitivos, en las funciones ejecutivas y toma de decisiones. Sin embargo, la evidencia encontrada en la revisión literaria que establece un perfil de las diferencias en la toma de decisiones en adolescentes consumidores de SPA comparado con adolescentes no consumidores es limitada, por lo cual, es pertinente realizar la comparación y descripción de los procesos relacionados y así estimar la afectación en la de toma de decisiones que apoye futuras investigaciones.

Por esta razón, el presente estudio utilizará como instrumento el IGT evaluando por medio de ensayo y error las consecuencias de las elecciones tomadas (Gordillo et al.2011) y así identificar si la toma de decisiones suele basarse por medio de impulsividad y con alto grado de riesgo, lo que permitirá 
establecer un perfil de la relación existente entre el consumo de SPA y los efectos sobre la toma de decisiones en adolescentes colombianos policonsumidores, comparados con un grupo control.

La investigación se enmarcó en el grupo Enlace de la Universidad Católica de Colombia y busca aportar desde la Línea de Investigación en Procesos Psicobiológicos y del Comportamiento. Teniendo en cuenta el anterior marco de referencia, se plantea el siguiente problema de investigación, ¿Existen diferencias en el rendimiento del proceso de la toma de decisiones entre un grupo de adolescentes colombianos policonsumidores de SPA y un grupo de no consumidores de SPA?

\section{Objetivos}

\section{Objetivo general}

Comparar el rendimiento en el proceso de toma de decisiones entre un grupo de adolescentes colombianos policonsumidores de sustancias psicoactivas y un grupo de adolescentes no consumidores, con características sociodemográficas similares.

\section{Objetivos específicos}

Describir el rendimiento en el proceso de toma de decisiones de un grupo de adolescentes colombianos policonsumidores de SPA.

Describir el rendimiento en el proceso de toma de decisiones de un grupo de adolescentes colombianos no consumidores de SPA.

Identificar las diferencias y semejanzas en el proceso de toma de decisiones entre adolescentes colombianos policonsumidores y no consumidores de SPA. 


\section{Método}

\section{Diseño}

En la presente investigación se utilizó un diseño de tipo comparativo ex post facto. Dichos estudios analizan las relaciones existentes entre variables y las diferencias que se pueden establecer entre dos o más grupos. Teniendo en cuenta que los estudios comparativos pueden variar dependiendo el enfoque, se implementó el diseño caso - control (DCC) el cual permite identificar entre dos grupos si muestra evidencia de la variable dependiente o no la muestran, y después se comparan (Ato, López \& Benavente, 2013).

\section{Variables}

\section{Variable independiente}

Policonsumo: entendido como la dependencia que experimenta un individuo debido al consumo repetitivo de tres o más sustancias psicoactivas durante un periodo de, al menos, 12 meses. Variable ordinal, medida a través de la prueba ASSIST 3.1, la cual otorga puntuación de bajo riesgo de consumo (0-3), moderado riesgo de consumo (4-26) y alto riego de consumo $(27+)$.

\section{Variable dependiente}

Toma de decisiones: Proceso cognoscitivo mediante el que se realiza alguna elección entre varias alternativas para poder resolver alguna situación que se presenta en un contexto. Variable nominal, medida a través de la prueba lowa Gambling Task, la cual permite establecer elecciones de alto riesgo (mayoría de respuestas de los mazos C y D) y de bajo riesgo (mayoría de elección de los mazos A y B). 


\section{Hipótesis}

$H_{1}$ : El grupo de adolescentes policonsumidores de SPA presenta una toma de decisiones de alto riesgo comparado con los adolescentes que no son consumidores.

$\mathrm{H}_{0}$ : El grupo de adolescentes policonsumidores de SPA no presenta una toma de decisiones de alto riesgo comparado con los adolescentes que no son consumidores.

\section{Participantes}

La muestra estuvo conformada por 14 adolescentes colombianos residentes en la ciudad de Bogotá, hombres y mujeres, escolarizados, con edades comprendidas entre los 16 y los 17 años, con estrato socioeconómico 2 y 3. Se diferencian dos grupos, el primero, estuvo compuesto por siete adolescentes policonsumidores (dos mujeres y cinco hombres) y el otro, por siete adolescentes no consumidores (cinco mujeres y dos hombres).

Los criterios de inclusión que se tuvieron en cuenta para formar parte de la muestra general se obtuvieron a partir de la historia clínica, estos datos fueron: ser colombiano y residir en la ciudad de Bogotá, encontrarse escolarizados en alguna institución de educación privada o distrital, pertenecer a estratos 2 o 3 , tener ausencia de enfermedad orgánica que pueda provocar déficit cognitivo o psicopatológico grave, ausencia de enfermedad física para realizar tareas requeridas, tener ausencia de deficiencias auditivas o visuales que no estuvieran corregidas y pudiesen afectar la realización de la prueba, no consumir algún medicamento prescrito por un médico y no tener antecedentes de participación en programas de rehabilitación de algún tipo. 
Para el grupo de policonsumidores se tuvo en cuenta, obtener una puntuación de 1 en el primer ítem de la escala ASSIST, tener historia de consumo de tres o más sustancias psicoactivas por un periodo de tiempo mínimo de 12 meses y máximo tres años. Dentro de las sustancias más consumidas reportadas, se encuentran inhalantes, tabaco, alcohol, cannabis, cocaína, sedantes y alucinógenos

En cuanto al grupo de no consumidores, se tuvo en cuenta obtener una puntuación 0 en el primer ítem de la escala ASSIST.

\section{Instrumentos}

\section{Historia clínica}

Instrumento diseñado para recolectar la información sociodemográfica, los antecedentes neurológicos, psicológicos, médicos y la historia de consumo de sustancias psicoactivas. Este instrumento se aplicó de manera conjunta con los participantes y se comprobó la información con padres y/o cuidadores principales (Apéndice A).

\section{Prueba de detección de consumo de alcohol, tabaco y sustancias ASSIST}

\section{1}

Prueba utilizada en ámbitos de atención primaria de salud (OMS, 2011). La versión 3.1 consiste en un cuestionario de ocho preguntas y su aplicación tiene una duración entre 5 y 10 minutos y permite detectar el consumo de las siguientes sustancias: tabaco, alcohol, cannabis, cocaína, estimulantes de tipo anfetamina, inhalantes, sedantes o pastillas para dormir (benzodiacepinas), alucinógenos, opiáceos y otras drogas (Apéndice B).

EI ASSIST permite identificar el puntaje de riesgo de la sustancia consumida, clasificando a los individuos en riesgo tipo bajo, moderado o alto. 
Para cada caso, brinda información sobre el consumo a lo largo de la vida y los problemas que se derivan de éste en los últimos tres meses. También sugiere posibilidades de intervención según el tipo de riesgo (OMS, 2011).

\section{lowa Gambling Task (IGT)}

Es una tarea psicológica para simular la toma de decisiones en la vida real diseñada por Bechara y Damasio (1994). A través de un juego este test le permite a los participantes aprender por medio de ensayo y error las consecuencias a corto y largo plazo de las elecciones que se realizan, sean beneficiosas o no.

El IGT consta de cuatro mazos de cartas denominados $A, B, C$ y $D$. Durante la tarea, las personas deben elegir una carta al azar que pueden hacerles ganar o perder dinero. Al girar alguna carta, esta tendrá una recompensa (ganar dinero) o un castigo (pagar dinero). Al elegir con mayor frecuencia los mazos $C$ y $D$ se obtienen beneficios a largo plazo, mientras que elegir los mazos A y B, dará pérdidas a largo plazo. Entre más ensayos se realicen, las personas suelen elegir los mazos que representan mayores ganancias ( $C$ y $D)$, pero que a su vez representan mayor número de pérdidas en proporción a las ganancias. Mientras que los otros dos mazos de cartas representan menor número de ganancias y las pérdidas son menores ( $\mathrm{A}$ y $B$ ). Las personas no tienen ideas previas acerca de cómo comportarse ante la elección de cada mazo, por lo tanto, las elecciones se realizarán dependiendo de la experiencia y retroalimentación emocional al recibir algún beneficio o castigo frente a las decisiones tomadas. En pocas palabras, para su aplicación, se presentan al sujeto cuatro mazos de cartas, hay mazos desfavorables en los cuales las ganancias y pérdidas son elevadas y 
favorables en los cuales la suma de dinero es menor, la tarea se ejecuta adecuadamente cuando el sujeto selecciona cartas de los mazos favorables (Mogedas \& Alamedas, 2011).

Para el presente estudio se utilizó la variación digital lowa Gambling Task, versión 2 (IGT2), con la interpretación y aplicaciones clínicas presentados en el Manual Profesional IGT2. Esta variación consiste en un programa "Cartas" computarizado basada en el IGT, en esta versión el jugador observa en la pantalla cuatro mazos de cartas A, B, C y D boca abajo y debe elegir libremente entre estos para ganar la mayor suma de dinero posible. Cada uno de los mazos está compuesto por 40 cartas y la tarea consta de un total de 100 ensayos. En la parte inferior de la pantalla, aparece la cantidad de dinero acumulada acompañado de los iconos + (si gana), - (si pierde) $0=($ si se queda igual).

Se parte de una suma inicial de $\$ 2000$. Los mazos A y B hacen ganar $\$ 100$ por jugada y las penalizaciones son de $\$ 1250$ cada diez jugadas obteniendo un saldo final de $\$-250$. Mientras que los mazos C y D proveen de ganancias $\$ 50$ y las pérdidas son de $\$ 250$ cada diez ensayos, con lo cual se obtiene un saldo positivo final de $\$ 250$. Por lo tanto, los mazos A y B son considerados como riesgosos ya que proveen mayor cantidad de dinero, aunque son penalizados con mayor número de castigos y proporciones de dinero. Los mazos $\mathrm{C}$ y $\mathrm{D}$ por su parte, se consideran mazos positivos, debido a que las elecciones son más estratégicas y cautelosas, permitiendo ganancias modestas y seguras. Para el análisis de resultados una puntuación o saldo positivo, significa que las decisiones tomadas son sin asumir riesgos, mientras que un saldo negativo 
significa que se han asumido muchos riesgos o que el desempeño en la ejecución es deficiente.

\section{Procedimiento}

Para el desarrollo del presente estudio se implementaron cuatro fases:

Fase 1. Se realizó la búsqueda y selección en la ciudad de Bogotá de los adolescentes participantes de la investigación a través de voz a voz. Luego, se explicó a los participantes y sus representantes legales el objetivo de la investigación, se les presentó el asentimiento, el consentimiento informado (Apéndice C y D) y se les hizo explícito la protección y preservación de los datos e identidad del participante (Apéndice E), se resolvieron las dudas e inquietudes y se procedió a la firma del consentimiento y asentimiento antes de iniciar.

Posteriormente, se realizó la entrevista inicial y se recolectó la información sociodemográfica por medio del formato de historia clínica. Finalmente, se aplicó la Prueba de Detección de Consumo de Alcohol, Tabaco y Sustancias (ASSIST 3.1) para esto se dispuso entre 5 y 10 minutos en los cuales se aplicó de forma individual a cada participante las ocho preguntas del ASSIST que identifican la experiencia sobre el consumo de sustancias lícitas e ilícitas a lo largo de la vida y el nivel de riesgo de consumo para cada una de ellas.

Fase 2. Se aplicó la prueba neuropsicológica lowa Gambling Task de la siguiente forma:

Inicialmente el participante se sentó de manera individual en una mesa frente a cuatro mazos de cartas de igual aspecto. Luego, se le proporcionaron las instrucciones y el objetivo de la tarea a realizar, especificando que se debe maximizar la cantidad de dinero. También, se explicó a los participantes que 
debían elegir algún mazo de cartas (A, $B, C \quad$ o $D)$ sin algún orden predeterminado y después de cada elección recibirán o perderán cierta cantidad de dinero. En el caso de las penalizaciones, el monto fue anunciado antes de proceder a la siguiente elección. Los mazos A y B son equivalentes en términos de pérdida global durante los ensayos, pero el castigo es más frecuente y de menor magnitud que en el mazo $B$. Los mazos $C$ y $D$ son equivalentes en términos de ganancia total, pero en el mazo $\mathrm{C}$ el castigo es más frecuente y de menor magnitud que en el mazo D.

Mientras el participante realizaba la tarea, el evaluador utilizó la tabla preprogramada de recompensa y castigo en la tarjeta para hacer el seguimiento de las elecciones de cartas marcando cada una de las 100 elecciones en la celda correspondiente. El participante es recompensado con la cantidad de dinero en la primera columna y se presenta con un castigo basado en la programación detallada en las siguientes columnas (Apéndice F).

Fase 3. Los datos obtenidos en los protocolos y baterías aplicados fueron tabulados mediante el programa estadístico SPSS versión 15.0, se aplicó la prueba de normalidad Saphiro-Wilk y se presentaron los datos estadísticos para su análisis mediante la prueba t-Student.

Fase 4. Se realizó el análisis de datos comparando la revisión teórica, discutiendo las relaciones de las variables encontradas y contrastando con los estudios actuales.

\section{Consideraciones éticas}

Esta investigación se realizó bajo el marco de los establecimientos legales y éticos que se presentan a continuación: 
Ley 1090 de 2006 que reglamenta "el ejercicio de la profesión de Psicología, se dicta el Código Deontológico y Bioético y otras disposiciones" (p.1). El desarrollo de la investigación se regirá conforme a las disposiciones y principios generales del ejercicio de la psicología, tales como: responsabilidad, competencia, estándares morales y legales, confidencialidad, bienestar del usuario, evaluación de técnicas e investigación con participantes humanos (Congreso de Colombia, 2006).

Resolución 8430 de 1993 del Ministerio de Salud de Colombia (1993) la cual dispone "las normas científicas, técnicas y administrativas para la investigación en salud" (p.1) en especial determina que la investigación con humanos se debe realizar bajo principios éticos y científicos, velando por la seguridad y protección de la privacidad de los participantes en la investigación. Por tal motivo, se hace uso del consentimiento informado firmado por parte del representante legal de los participantes y el asentimiento informado por los participantes; estos documentos avalan la participación libre y voluntaria, la posibilidad de retirarse de la investigación si se desea, la suspensión del proceso si existe algún riesgo, el derecho a recibir la retroalimentación de los resultados y que estos serán utilizados únicamente con carácter académico (Apéndice C y D).

Ley estatutaria 1266 de 2008 "por la cual se dictan las disposiciones generales del habeas data y se regula el manejo de la información contenida en bases de datos personales, en especial la financiera, crediticia, comercial, de servicios y la proveniente de terceros países y se dictan otras disposiciones" (p.1) (Apéndice E). (Congreso de la República de Colombia, 2008). 


\section{Análisis de resultados}

Se realizó un análisis descriptivo de la ejecución de los participantes en los ensayos de la IGT, con el fin de identificar las puntuaciones totales de la tarea. A través del programa estadístico SPSS v. 15.0 se hizo el análisis estadístico utilizando la prueba Shapiro-Wilk para determinar la normalidad y la t Student con el fin de identificar por cuál de las barajas se inclinaban los adolescentes de ambos grupos.

\section{Resultados}

Los grupos de la muestra estuvieron conformados de manera tal que fueran pares en sus variables sociodemográficas (edad, sexo, tipo de institución educativa y estrato socioeconómico). No se determinaron diferencias significativas entre los grupos, con lo cual se confirmó igualdad estadística, estableciéndose así confiabilidad en cuanto a los análisis comparativos intergrupos. En la tabla 1 se muestran las características estadísticas de los grupos de policonsumidores y no consumidores. 
Tabla 1. Datos sociodemográficos descriptivos en función del grupo de policonsumidores y no consumidores

\begin{tabular}{|c|c|c|c|c|c|}
\hline & & \multicolumn{2}{|c|}{$\begin{array}{l}\text { Policonsumidores } \\
\qquad N=7\end{array}$} & \multicolumn{2}{|c|}{$\begin{array}{c}\text { No consumidores } \\
N=7\end{array}$} \\
\hline & & Frecuencia & $\%$ & Frecuencia & $\%$ \\
\hline \multirow[t]{3}{*}{ Sexo } & Mujer & 2 & 71,4 & 5 & 28,6 \\
\hline & Hombre & 5 & 28,6 & 2 & 71,4 \\
\hline & $\mathbf{N}$ & 7 & & 7 & \\
\hline \multirow[t]{3}{*}{ Edad } & $\mathbf{M}$ & 17 & & 16,85 & \\
\hline & DT & .000 & & .377 & \\
\hline & $\mathbf{N}$ & 7 & & 7 & \\
\hline \multirow{3}{*}{$\begin{array}{l}\text { Tipo de } \\
\text { institución } \\
\text { educativa }\end{array}$} & Privada & 6 & 85,7 & 6 & 85,7 \\
\hline & Pública & 1 & 14,3 & 1 & 14,3 \\
\hline & $\mathbf{N}$ & 7 & & 7 & \\
\hline \multirow{3}{*}{$\begin{array}{l}\text { Estrato } \\
\text { socioeconómico }\end{array}$} & 2 & 2 & 28,6 & 1 & 14,3 \\
\hline & 3 & 5 & 71,4 & 6 & 85,7 \\
\hline & $\mathrm{N}$ & 7 & & 7 & \\
\hline
\end{tabular}

Con relación a la variable dependiente (toma de decisiones), las repuestas de los adolescentes de ambos grupos fueron analizadas con el paquete estadístico SPSS versión 15.0. Primero, se hizo un análisis de normalidad de los datos con la prueba Shapiro-Wilk con la cual se estableció que todas las dimensiones de la variable se distribuían normalmente, ya que el nivel de significancia para todos los mazos fue superior a 0.05 , como lo muestra la tabla 2, confirmando esto que no existen diferencias significativas en la distribución de los datos.

Tabla 2. Prueba de normalidad Shapiro-Wilk para la elección de mazos del IGT

\begin{tabular}{clccc}
\multirow{2}{*}{ Mazos } & \multirow{2}{*}{ Grupo } & \multicolumn{3}{c}{ Shapiro-Wilk } \\
\cline { 3 - 5 } & & Estadístico & gl & Sig. \\
\hline \multirow{2}{*}{ IGTA } & Policonsumidor &, 936 & 7 &, 605 \\
\cline { 3 - 5 } IGTB & No consumidor &, 825 & 7 &, 071 \\
\cline { 3 - 5 } Policonsumidor &, 875 & 7 &, 206
\end{tabular}




\begin{tabular}{cllll}
\multirow{2}{*}{ IGTC No consumidor } &, 923 & 7 &, 494 \\
\multirow{2}{*}{ IGTD } & Policonsumidor &, 808 & 7 &, 050 \\
\cline { 2 - 4 } & No consumidor &, 913 & 7 &, 419 \\
& Policonsumidor &, 909 & 7 &, 389 \\
\cline { 2 - 4 } & No consumidor &, 917 & 7 &, 445 \\
\hline
\end{tabular}

Gracias a que los datos obtenidos en la prueba Shapiro-Wilk arrojaron una distribución normal, se optó por un análisis estadístico paramétrico para muestras independientes, en este caso la prueba t de Student reportado en la tabla 4.

Tabla 3. Prueba T-Student del grupo de policonsumidores y no consumidores en el lowa Gambling Task

\begin{tabular}{cccccc}
\hline $\begin{array}{c}\text { Barajas de cartas } \\
\text { IGT }\end{array}$ & Policonsumidor & No consumidor & & \\
\hline & $(\mathrm{Dt})$ & $(\mathrm{Dt})$ & $\mathrm{T}$ & $\mathrm{gl}$ & $\mathrm{p}$ \\
\cline { 2 - 5 } IGTA & $30,86(7.81)$ & $20,29(8,18)$ & 2,47 & 12 & 0,02 \\
IGTB & $31,71(10,37)$ & $29,86(14,19)$ & 0,28 & 12 & 0,78 \\
IGTC & $20,43(8,97)$ & $26,86(10,38)$ & $-1,23$ & 12 & 0,23 \\
IGTD & $16,43(3,15)$ & $26,71(6,72)$ & $-3,66$ & 12 & 0,00 \\
\hline
\end{tabular}

Los datos sugieren que existen diferencias significativas en el mazo A de las cartas del IGT, en el cual los policonsumidores tuvieron mayor puntuación y en el mazo D del IGT el cual fue de preferencia en su mayoría por los no consumidores, esto sugiere que los adolescentes policonsumidores eligieron más el mazo desventajoso que representaba mayor ganancia a corto plazo y pérdidas superiores a largo plazo y los adolescentes no consumidores eligieron con mayor frecuencia el mazo que representó más ganancia a largo plazo; mientras que en los mazos $\mathrm{B}$ y el $\mathrm{C}$ no se hallaron diferencias significativas.

\section{Discusión}

En los últimos tiempos, el estudio de la toma de decisiones ha sido relevante, tras la creación del IGT, se intenta establecer la influencia que tienen 
los factores emocionales, midiendo los marcadores somáticos en los procesos decisivos (Acuña, et al., 2013; Bechara et al., 2003; Muñoz, 2011). Teniendo en cuenta que la tarea del IGT, está basada en la teoría del marcador somático (TMS), que indica que, a partir de las asociaciones de experiencias pasadas y la generación de respuestas fisiológicas, los mecanismos asociados a este proceso sesgan las decisiones al reducir la probabilidad de tomar determinada elección que ha sido asociada a un marcador negativo. Es por esto que se asume que las emociones interfieren en el proceso cognitivo que guía la conducta, dando una cualidad positiva o negativa en la adaptabilidad del individuo en el contexto en que se desenvuelve (Bechara, Damasio, \& Damasio, 2003).

El objetivo de la presente investigación fue comparar el rendimiento en el proceso de toma de decisiones en adolescentes policonsumidores y no consumidores. Los resultados mostraron que la toma de decisiones se ve afectada en la ejecución de la tarea del IGT en los adolescentes policonsumidores mostrando menor rendimiento en el proceso de toma de decisiones comparado con el grupo de no consumidores, lo cual, se evidencia en las elecciones desventajosas de la baraja A. Durante la ejecución de la tarea del IGT, los adolescentes policonsumidores realizaron menos elecciones de las cartas ventajosas, inclinándose con mayor frecuencia por las barajas A y $B$, es decir, los mazos que más puntos les suministraban de manera inmediata y que a la vez les representaban mayor porcentaje de pérdida o penalización. Por otra parte, los adolescentes no consumidores mostraron una mayor inclinación por la elección de los mazos D, es decir, las barajas que representaban una recompensa inmediata menor y mayor ganancia futura, 
eligiendo cada vez un número de cartas desventajosas menor durante la aplicación. Mientras que no hubo una diferencia significativa en la elección de los mazos B y $\mathrm{C}$ entre ambos grupos.

Lo anterior, demuestra que el grupo de adolescentes no consumidores lograron aprender a identificar los niveles de castigo y recompensa de cada una de las barajas de cartas, lo cual significa que anticiparon las consecuencias a futuro o prospectivas de las decisiones que toman. Mientras que, los adolescentes policonsumidores tuvieron un desempeño basado en incertidumbre, provocando que las elecciones no fueran favorables y que no tuvieran consciencia de las consecuencias de las ganancias, es decir, mostraron baja sensibilidad al castigo, impidiendo e interfiriendo en el procesamiento de retroalimentación y aprendizaje de la tarea, esta impulsividad es una consecuencia del consumo (López, Rodríguez, Cadaveira, Corral \& Doallo, 2013).

Para ejecutar adecuadamente la tarea del IGT se debe tener consolidada la capacidad de establecer relaciones de estímulo-recompensa y la habilidad para cambiar o eliminar respuestas que se han aprendido con anterioridad. Con base en los resultados de estudios anteriores, la diferencia en las respuestas con los grupos control y los de estudio, se explica por la capacidad de alterar o invertir los aprendizajes previos. Por su lado, el grupo control al haber aprendido las contingencias de cada mazo, son capaces de invertir en el aprendizaje inicial e inhibir las respuestas de elección del mazo A y B, aumentando la probabilidad de elección de los mazos C y D.

Por otra parte, el consumo de SPA se ha visto relacionado con alteraciones cognitivas y el patrón conductual de los consumidores se caracteriza por actuar 
bajo las consecuencias inmediatas a pesar de que estas sean negativas, por lo que pueden asociarse al déficit cognitivo frente a las posibilidades de un individuo para inhibir respuestas, afrontar con éxito actividades diarias bajo el efecto de la sustancia consumida (Mogedas-Valladares et al., 2011). Con respecto a los resultados, las diferencias en la toma de decisiones se relacionan con la neurotoxicidad producida por las SPA consumidas, ya que éstas afectan las emociones interfiriendo con la capacidad de evaluar la elección de los mazos, por lo cual, los adolescentes policonsumidores elegían basándose en qué mazos les daban mas ganancia en el momento y a diferencia los adolescentes no policonsumidores elegían centrándose en identificar qué mazos mantenían la ganancia a largo plazo (Dante, 2006).

Los resultados evidencian una dificultad en el grupo de adolescentes para generar señales emocionales que se relacionaban con las pérdidas, que les permiten aprender y reorientar las respuestas prospectivas de selección que reemplace las pérdidas grandes por ganancias futuras, en consecuencia, se fijaron las respuestas en los mazos desventajosos. Por el contrario, el grupo de no consumidores pudo modificar el marcador somático de decisiones basándose en las contingencias de los mazos de cartas, decidiendo al final, las barajas de mayor ganancia a largo plazo.

La capacidad limitada en el proceso de toma de decisiones antecede y se asocia con las alteraciones cognitivas asociadas al policonsumo de SPA, corroborando la hipótesis de que existen diferencias en la toma de decisiones de adolescentes policonsumidores y no consumidores. Los adolescentes policonsumidores que presentan dificultades en la toma de decisiones son incapaces de decidir en situaciones cotidianas, tomando elecciones 
inapropiadas, impulsivas y riesgosas, que si bien pudieron ser adecuadas en algún momento, en la situación actual no lo son. El fenómeno evidenciado, corrobora la hipótesis del marcador somático y las dificultades en la toma de decisiones ventajosas en consumidores derivadas por la falta o deficiencias en los mecanismos emocionales que permiten anticipar las respuestas y los resultados de una elección (Regal et al., 2017; Gómez, 2006; Sánz, 1996).

Las investigaciones realizadas sobre toma de decisiones en consumidores de SPA muestran resultados similares, encontrando alteraciones o lesiones cerebrales en áreas orbitofrontales, el cual está directamente relacionado con el procesamiento y la interpretación del contexto social, personal y emocional de un individuo. Aunque la toma de decisiones se relaciona con áreas ventromediales, la amígdala y núcleo acummbens, el área orbitofrontal es la integradora de los procesos cognitivos y emocionales que intervienen en la toma de decisiones (Sarmiento- Rivera \& Ríos-Flórez, 2017; Chimbo, 2014; Ardila \& Ostrosky, 2008).

Resultados similares de la impulsividad en la toma de decisiones asociado al consumo de SPA se evidenciaron en el estudio de Trillos, Tamayo y Artunduaga, 2020 encontrando correlación entre la toma de decisiones y el consumo, puesto que la tendencia de elección era elegir alternativas con recompensas inmediatas en lugar de las ganancias a largo plazo.

Los resultados obtenidos en el IGT en el grupo de policonsumidores podrían explicarse por la desconexión funcional o alteraciones en el córtex órbitofrontal y con las estructuras subcorticales que se involucran en el proceso de toma de decisiones. Además, se puede evidenciar que actúa bajo una 
miopía ante el futuro, lo que conlleva a los adolescentes a orientarse por los mazos desventajosos.

Hacia futuro se crea la necesidad de realizar el estudio con una muestra más amplia e incluir más variables que evalúen el proceso cognitivo y emocional, tener en cuenta los componentes y funciones ejecutivas que se relacionan con la toma de decisiones. Además, dentro de los criterios de inclusión para el grupo de policonsumidores, sería pertinente que tuvieran un riesgo de consumo alto ya que el nivel de daño o alteración cognitiva sería mayor. También, para el análisis de resultados y variables, se debe considerar la etapa madurativa en que se encuentran los adolescentes, ya que en esta edad las decisiones suelen ser impulsivas y riesgosas ya que el córtex prefrontal no está desarrollado en su totalidad, es por lo que, aunque se encontraron diferencias entre ambos grupos, no son tan significativas. 


\section{Referencias}

Acosta L, J., Cervantes, M. L., Pineda, W. F., De la Torre Pe, G., López, L., \& Cárdenas. (2011). Policonsumo desde una perspectiva neuropsicológica. Psicogente, 14(25), 178-189. Recuperado de: http://revistas.unisimon.edu.co/index.php/psicogente/article/view/1865

Acosta, M., Juárez, F., \& Cuartas, M. (2018). Funciones ejecutivas y antecedentes familiares de alcoholismo en adolescentes. Pensamiento Psicológico, 16 (1), 57-68. Recuperado de: http://revistas.javerianacali.edu.co/index.php/pensamientopsicologico/articl e/view/1579/2300

Acosta, R., Cuartas, M., \& Juárez, F. (2017). Revisión sistemática de modelos neurobiológicos y ejecutivos en alcoholismo. Psychologia. Avances de la Disciplina, 11 (1), 71-84. http://dx.doi.org/10.21500/19002386.3103

Acuña, I., Castillo, D., Bechara, A., \& Godoy, J. (2013). Toma de decisiones en adolescentes: rendimiento bajo diferentes condiciones de información e intoxicación alcohólica. International Journal of Psychology and Psychological Therapy, 13(2), 195-214. Recuperado de: http://www.redalyc.org/pdf/560/56027416004.pdf

Acuña, P., \& Rivera, P. (2009). Características Neuropsicológicas de Adolescentes Policonsumidores de Sustancias Psicoactivas (tesis). Universidad San Buenaventura. Bogotá, Colombia. Recuperado de: http://biblioteca.usbbog.edu.co:8080/Biblioteca/BDigital/44487.pdf

Alameda-Bailén, J., Salguero-Alcañiz, M., Merchán-Clavellino, A., \& PaínoQuesada, S. (2014). Mecanismos cognitivos en la toma de decisiones arriesgadas en consumidores de cannabis. Adicciones, 26 (2), 146- 
158. Recuperado

de:

https://pdfs.semanticscholar.org/d973/a144d07c46a46eda86255a1b84f86 1cf5504.pdf

Alameda, J., Quesada, S., \& Mogedas, A. (2012). Toma de decisiones en consumidores de cannabis. Adicciones. 24(2), 161-172. Recuperado de: http://www.adicciones.es/index.php/adicciones/article/view/109

Alcántara, C., \& Molero, V. (2010). La emoción y los marcadores somáticos: Un modelo de decisión de compra. Recuperado de: https://www.academia.edu/11326305/La_Emocio_n_y_los_Marcadores_S oma_ticos_Un_Modelo_de_Decisio_n_de_Compra

Ardila, A., \& Ostrosky, F. (2008). Desarrollo Histórico de las Funciones Ejecutivas. Revista Neuropsicología, Neuropsiquiatría y Neurociencias .8 (1). $1-21$.

Recuperado

de: https://dialnet.unirioja.es/servlet/articulo?codigo=3987433

Ardila, A., \& Rosselli, M. (2007). Neuropsicología Clínica. México, Manual Moderno.

Arias, J., Rodríguez A., \& García, J. (2017). La enseñanza en vilo de las emociones: una perspectiva emocional de la educación. Recuperado de: http://www.scielo.org.co/scielo.php?script=sci_arttext\&pid=S012312942017000300451

Arias, R. (2005). Reacciones fisiológicas y neuroquímicas del alcoholismo. $\begin{array}{llll}\text { Diversitas. } & 1 & \text { (2), } & \text { 138-147. Recuperado }\end{array}$ http://www.scielo.org.co/pdf/dpp/v1n2/v1n2a03.pdf

Arteaga, D., G., \& Quebradas, A. (2010). Funciones ejecutivas y marcadores somáticos: apuestas, razón y emociones. El Hombre y la Máquina, (34), 
115-129. Recuperado

de:

http://www.redalyc.org/articulo.oa?id=47817108012

Asociación Americana de Psiquiatría (APA). (2014). Manual Diagnóstico y

Estadístico de los Trastornos Mentales: DSM-5 (5th ed.). Madrid, España: Médica Panamericana.

Ato, M., López, J., \& Benavente, A. (2013). Un sistema de clasificación de los diseños de investigación en psicología. Anales de Psicología, 29(3), 1038-1059. doi:10.6018/analesps.29.3.178511

Bahena, R., Flores, G., \& Arias, J. (2000). Dopamina: síntesis, liberación y receptores en el Sistema Nervioso Central. Revista Biomed, (11).39-60. Recuperado de: http://www.revbiomed.uady.mx/pdf/rb001116.pdf

Bechara, A. (2004). The role of emotion in decisión-making: Evidence from neurological patients with orbitofrontal damage. Brain and Cognition. 5530-40. Recuperado de: https://www.its.caltech.edu/ squartz/bechara.pdf

Bechara, A., Damasio, H., \& Damasio, A. (2003). Role of the amygdala in decision-making. Recuperado de: https://nyaspubs.onlinelibrary.wiley.com/doi/pdf/10.1111/j.17496632.2003.tb07094.x

Bechara, A., Damasio, H., Tranel, D., \& Damasio, A. (1997). Deciding advantageously before knowing the advantageous strategy. Recuperado de: https://www.ncbi.nlm.nih.gov/pubmed/9036851

Bechara, A., Damasio, A., Damasio, H \& Anderson, S. (1994). Insensitivity to future consequences following damage to human prefrontal cortex. Cognition. 50. 7-15. Recuperado de: http://www.antoniocasella.eu/dnlaw/bechara_1994.pdf 
Becoña, E., \& Cortés, M. (2010). Manual de adicciones para psicólogos especialistas en psicología clínica en formación. Barcelona, Socidrogalcohol.

Bernal, L., Antonio, A., Arocena, L., \& Vicente, F. (2014). Patrones de toma de decisiones y autoconfianza en adolescentes bachilleres. Revista de Psicología, 32(1). 39-65. Recuperado de: http://www.redalyc.org/articulo.oa?id=337831261002

Beverido, B. (2010). Consumo de marihuana y sus efectos en la salud mental y las habilidades cognitivas necesarias para el aprendizaje. Revista Médica de la Universidad Veracruzana, 10(2), 49-53. Recuperado de: https://www.uv.mx/rm/num_anteriores/revmedica_vol10_num2/articulos/C onsumoMariguana.pdf

Bonet, J., Salvador, A., Torres, C., Aluco, E., Cano, M., \& Palma, C. (2015). Consumo de cocaína y estado de las funciones ejecutivas. Revista Española de Drogodependencia. 40(2), 13-23. Recuperado de: http://www.aesed.com/descargas/revistas/RED_40-2.pdf Bonilla-Santos, J., González-Hernández, A., Bonilla-Santos, G., Muñoz-Bernal, L., \& Baldovino, I. (2017). Toma de decisiones en menores con factores de riesgo para el Trastorno Disocial de la Conducta. Revista Médica de Risaralda, 23 (1). Recuperado de: http://dx.doi.org/10.22517/25395203.12311

Broche, Y., \& Cruz, D. (2014). Toma de decisiones en la adolescencia: Entre la razón y la emoción. Ciencia Cognitiva, 8(3), 70-72. Recuperado de: https://www.researchgate.net/publication/277010161_Toma_de_decisione s_en_la_adolescencia_Entre_la_razon_y_la_emocion 
Broche, Y., Herrera, L., \& Martínez, E. (2014). La hipótesis del marcador somático y el IGT: bases neurales de la toma de decisiones. Recuperado de:

https://www.researchgate.net/publication/267748527_LA_HIPOTESIS_DE L_MARCADOR_SOMATICO_Y_EL_IGT_BASES_NEURALES_DE_LA_T OMA_DE_DECISIONES

Broche-Pérez, Y., Díaz, C. A., \& Rodríguez, A. (2015). Tarea de apuestas flexible (FlexGT): plataforma automatizada para el estudio de la toma de decisiones. Revista Cubana Neurología Neurocirugía. 5(1), 49-55. Recuperado de: http://www.revneuro.sld.cu/index.php/neu/article/view/247 Broche-Pérez, Y., Díaz, C. A., \& Rodríguez, A. (2015). Toma de decisiones en jóvenes con conductas antisociales: Evidencias desde el lowa Gambling Task. Neurol. Arg. 7 (3). 140.147. Recuperado de: https://www.researchgate.net/publication/276292638_Toma_de_decisione s_en_jovenes_con_conductas_antisociales_Evidencias_desde_el_lowa_ Gambling_Task

Calle, D. (2017). Filogenia y desarrollo de funciones ejecutivas/ Phylogeny and executive functions development. Psicogente, 20(38). Recuperado de: https://doi.org/10.17081/psico.20.38.2557

Camelo, S., Olivares, T., \& Carballeira, M. (2016). Funciones ejecutivas y ajuste clínico en adolescentes colombianos policonsumidores. Tesis doctoral. Universidad de La laguna. Recuperado de: https://www.researchgate.net/publication/334683907_Funciones_Ejecutiv as_y_Ajuste_Clinico_en_Adolescentes_Colombianos_Policonsumidores 
Castrillón, R. (2018). Programa de entrenamiento deportivo basado en el análisis neurocientífico de la toma de decisiones en niños de 9 a 12 años. Universidad San Francisco De Quito USFQ. Recuperado de:

Casey, B., Getz, S y Galvan, A. (2008). The adolescent brain. Developmental Review. 28 (1), 62.77.

Chimbo, E. (2014). La drogodependencia y su influencia en la capacidad para la toma de decisiones (tesis especialización), Universidad Central del Ecuador. Quito, Ecuador.

Congreso de Colombia. (2006). Código Deontológico y Bioético y otras disposiciones. (Ley 1090 del 2006). Recuperado de: https://docs.supersalud.gov.co/PortalWeb/Juridica/Leyes/L1090006.pdf

Congreso de la República. (2008). Ley Estatutaria No. 1266 Habeas Data. Recuperado de: http://lenguaje.mintic.gov.co/sites/default/files/archivos/ley_estatutaria_12 66_de_2008.pdf

Corominas, M., Roncero, C., Bruguera, E., \& Casas, M. (2007). Sistema dopaminérgico y adicciones. Revista Neurológica. 44. 23-31. Recuperado de: https://www.neurologia.com/articulo/2006222

Damasio, A. (1998). Emotion in the perspective of an integrated nervous system. Brain Research Reviews. 26. 83-86. Recuperado de: http://www.bristoltherapyclinic.com/assets/emotion-in-the-perspective-ofan-integrated-nervous-system.pdf

Dante, C. (2006). Patrón de toma de decisiones desventajosas en pacientes drogodependientes. Salud y Drogas, 6 (1), 71-88. Recuperado de: http://dspace.aeipro.com/xmlui/handle/123456789/378 
Faílde, J., Dapía, M., Alonso, A., \& Pazos, E. (2015). Consumo de drogas en adolescentes escolarizados infractores. Educación XX1: Revista de la Facultad de Educación, 18 (2), 167-188

Flórez, J., Castillo, R., \& Jiménez, N. (2014). Desarrollo de funciones ejecutivas, de la niñez a la juventud. Anales de Psicología, 30(2), 463473. Recuperado de: http://dx.doi.org/10.6018/analesps.30.2.155471

Flórez, J., \& Ostrosky, F. (2008). Neuropsicología de lóbulos frontales, funciones ejecutivas y conducta humana. Revista Neuropsicología, Neuropsiquiatría y Neurociencias. 8 (1), 47-58. Recuperado de: https://dialnet.unirioja.es/servlet/articulo?codigo=3987468

Gambara, H., \& González, E. (2002). ¿Qué y cómo deciden los adolescentes? Tarbiya, Revista de Investigación e Innovación Educativa, (34),5-69. Recuperado de: https://revistas.uam.es/tarbiya/article/view/7330

García, A., Tirapu, J., Luna, P., Ibáñez, J., \& Duque, P. (2010). Son lo mismo inteligencia y funciones ejecutivas. Revista de Neurología, (50), 738-746. Recuperado de: https://pavlov.psyciencia.com/2013/10/Inteligencia-yjunciones-ejecutivas.pdf

García-Molina, A., Rodríguez, P., Vendrell, P., Junqué, C., \& Roig-Rovira, T. (2008). Disfunción orbitofrontal en la esclerosis múltiple: lowa GamblingTask. Psicothema, 20(3), 445-449. Recuperado de: http://www.psicothema.com/pdf/3506.pdf

Gómez, C. (2006). Patrón de toma de decisiones desventajosas en pacientes drogodependientes. Salud y Drogas, 6 (1). 71-88 Recuperado de. http://www.redalyc.org/pdf/839/83960104.pdf 
González, M., Ponce, J., Díaz, F., \& Marino, J. (2010). Influencia de Variables Cognitivas en el lowa GamblingTask. Revista Argentina de Ciencias del Comportamiento, 2(2), 32-42. Recuperado de: https://revistas.unc.edu.ar/index.php/racc/article/view/5261

Gordillo, F., Arana, J. M., Salvador, J., \& Mestas, L. (2011). Emoción y toma de decisiones: teoría y aplicación de la lowa GamblingTask. Revista Electrónica de Psicología Iztacala. 14(1), 333-353. Recuperado de:https://www.researchgate.net/publication/235411606_Emocion_y_toma _de_decisiones_teoria_y_aplicacion_de_la_lowa_Gambling_Task

Gordillo, F., Salvador, J., Arana J., Mestas, L., Meilán, J., Carro, J., \& Pérez E. (2010). Estudio de la toma de decisiones en una variante de la lowa GamblingTask. Revista Electrónica de Motivación y Emoción. 13(34). Recuperado de: https://dialnet.unirioja.es/servlet/articulo?codigo=3269790 Guerra, J. (2011). El abuso del consumo de sustancias psicoactivas en gestantes. Umbral Científico, (18), 69-85. Recuperado de: http://www.redalyc.org/pdf/304/30421523010.pdf

Herrera, E. (2007). Implicaciones de las conexiones virtuales y subcorticales del lóbulo frontal en la conducta humana. Universidad Autónoma de San Luis Potosí México. 6(17), 1-17. Recuperado de: https://www.researchgate.net/publication/28212482_Implicaciones_de _las_conexiones_cortico_y_subcorticales_del_lobulo_frontal_en_la_cond ucta_humana

Jiménez, O., \& Salcido, L. (2018). Emoción, toma de decisiones y mindfulness. Recuperado de: https://alternativas.me/attachments/article/177/1- 
\%20Emoci\%C3\%B3n,\%20toma\%20de\%20decisiones\%20y\%20mindfulne ss.pdf

Juárez, G. (2019). La huella del placer: De la regulación a la adicción.México: Manual Moderno.

Kentaro, K., Yoshi-Taka, M., Tomomi F., Kenichi U., Takeshi A., Chisato S., Kang C., Kazuo O., \& Masato, O. (2015) Neural basis of decision making guided by emotional outcomes. Journal of Neurophysiology. 113(9), 30563068.

Korlinova, T., Chumakova, M., \&Kornilov, S. (2018). Tolerance and Intolerance for Uncertainty as Predictors of Decision Making and Risk Acceptance in Gaming Strategies of The lowa Gambling Task. Psychology in Russia: State of the Art 11 (3). Recuperado de: http://psychologyinrussia.com/volumes/pdf/2018_3/psych_3_2018_6_Korn ilova.pdf

Kumar, R., Kumar, K., \& Benegal, V.(2019). Procesos de toma de decisiones subyacentes en lowa GamblingTask. Revista asiática de psiquiatría. 39,63-69. https://doi.org/10.1016/j.ajp.2018.12.006

Leijenhorst, L., Gunther, B., Macks, Z., Rombouts, S., Westenberg, P \& Crone, E. (2010). Adolescent risky decision-making: Neurocognitive development of reward and control regions. Neurolmage Volume 51, Issue 1, p.p 345-355. doi: 10.1016/j.neuroimage.2010.02.038.

Londoño, A. (2017). Actividad electrodérmica aplicada a la psicología: análisis bibliométrico. Revista Mexicana de Neurociencia.18 (4). 46-56. Recuperado de: http://revmexneuroci.com/wpcontent/uploads/2017/09/RevMexNeuroci_2017_18(4)-46-56-(R).pdf 
Malfáz, M., \& Salchis, M. (2007). Sistema de toma de decisiones basado en emociones y autoaprendizaje para agentes sociales autónomos. Tesis doctoral. Recuperado de: http://Tesis_Maria_Malfaz_Vazquez.pdf

Manes, F., \& Torralba, T. (2005). Funciones ejecutivas y trastornos del lóbulo frontal. Revista de Psicología 1(2), 30-52. Recuperado de: http://bibliotecadigital.uca.edu.ar/repositorio/revistas/funciones-ejecutivastrastornos-lobulo-frontal.pdf

Mantero, G. (2018). Sistema de recompensa del cerebro y neuronas de placer. Recuperado de: https://idus.us.es/xmlui/bitstream/handle/11441/82033/TFG\%20Sistema\% 20de\%20Recompensa\%20del\%20cerebro\%20y\%20neuronas\%20del\%20 placer\%20\%28Gonzalo\%20Mantero\%20Su\%C3\%A1rez\%29.pdf?sequenc e=1\&isAllowed $=y$

Marino, D., \& Julián, C. (2010). Actualización en Tests Neuropsicológicos de Funciones Ejecutivas. Revista Argentina de Ciencias del Comportamiento, 2(1), 34-45. Recuperado de: https://www.redalyc.org/articulo.oa?id=333427068004

Mariño, N., Castro, J., \& Torrado, J. (2012). Funcionamiento ejecutivo en policonsumidores de sustancias psicoactivas. Revista de Psicología Universidad de Antioquia. 4(2), 49-63. Recuperado de: http://aprendeenlinea.udea.edu.co/revistas/index.php/psicologia/article/vie wFile/15480/13607

Martínez, A., Molero, M., Barragán, M., Sánchez, C., Perez, M., \& Gázques, J. (2016). La toma de decisiones en conductas de riesgo de consumo de 
drogas en adolescentes a través de historias interactivas. Recuperado de: http://hdl.handle.net/10045/63889

Martínez, J., Sánchez, J., Bechara, A., \& Román, F. (2006). Mecanismos cerebrales de la toma de decisiones. Revista Neurológica. 42 (7). 411418. http://mecanismostd__ 701d6bc8599940e59adbb995a155972a_49_.p $\mathrm{df}$

Martínez, V., Fernández, J., La Torre, A., \& Fernández, S. (2018). Trayectorias de policonsumo y diferencias en impulsividad entre adolescentes. Revista Internacional de Psicología Clínica y de la Salud. 13(3), 235-244. Recuperado de: DOI: 10.1016 / j.ijchp.2018.07.003

Martos-Martínez, A., Molero-Jurado, M., Pérez-Fuentes, M., Gázquez Linarez, J \& Simón-Márquez, M. (2016). Frecuencia en el consumo de sustancia y relaciones entre iguales en población adolescente. European Journal of Child Development, Education and Psychopathology, 4(2), 75-87. https://doi.org/10.30552/ejpad.v4i2.36

Márquez, M., Salguero, P., Paíno, S., \& Alameda, J. (2013). La hipótesis del marcador somático y su nivel de incidencia en el proceso de toma de decisiones Revista Electrónica de Metodología Aplicada. 18(1), 17-36. Recuperado de: https://dialnet.unirioja.es/descarga/articulo/4107784.pdf Melo, A. (2010). Cerebro, mente y consciencia. Estados Unidos: iMedPub. Méndez, M., Romero, B., Cortés, J., Ruíz, A., \& Próspero, O. (2016). Neurobiología de las adicciones. Revista de la Facultad de Medicina de la UNAM. Recuperado de: https://www.medigraphic.com/pdfs/facmed/un2017/un171b.pdf 
Merchan, A. (2014). Efectos neuropsicológicos del consumo de drogas legales en jóvenes universitarias. (Tesis doctoral). Universidad de Huelva. España.

Michelini, Y., Acuña, I., \& Godoy, J. (2016). Emociones, toma de decisiones y consumo de alcohol en jóvenes universitarios. Suma Psicológica, 23 (1), 42-50. Recuperado de: http://www.redalyc.org/articulo.oa?id=134245262006

Ministerio de Salud. (1993). Resolución No. 8430. Recuperado de: https://www.minsalud.gov.co/sites/rid/Lists/BibliotecaDigital/RIDE/DE/DIJ/ RESOLUCION-8430-DE-1993.PDF

Mogedas-Valladares, A., \& Alameda-Bailén, J. (2011). Toma de decisiones en pacientes drogodependientes. Adicciones, 23(4), 277-287. Recuperado de: http://www.redalyc.org/articulo.oa?id=289122824002

Moussa, M., Wesley, M., Porrino, L., Hayasaka, S., Bechara, A., Burdette., \& Laurienti, P. (2014). Age-related differences in advantageous decision making are associated with distinct differences in functional community structure. Brain Connectivity, 4(3), 193-202. Recuperado de: https://search-proquest-

com.ucatolica.basesdedatosezproxy.com/docview/1516170581/51CB9778 ODBF4EEDPQ/4?accountid=45660\#center

Muñoz, J. (2011). Las funciones ejecutivas en subtipos de drogodependientes en tratamiento. Psicopatología Clínica, Legal y Forense. 11(1), 29-50. Recuperado de: https://dialnet.unirioja.es/servlet/articulo?codigo=6383206 Murgich, V. (2017). La influencia de los mecanismos reguladores de las emociones en la toma de decisión de compra en mujeres: Un estudio con 
resonancia magnética funcional por imagen (fMRI). Universidad Complutense de Madrid. Recuperado de: https://eprints.ucm.es/41931/1/T38580.pdf

Nuño, B. \& Flores, F. (2004). La búsqueda de un mundo diferente. La representación social que determina la toma de decisiones en adolescentes mexicanos usuarios de drogas ilegales. Recuperado de: https://www.researchgate.net/publication/26476563_La_busqueda_de_un _mundo_diferente_La_representacion_social_que_determina_la_toma_de _decisiones_en_adolescentes_mexicanos_usuarios_de_drogas_ilegales

Observatorio de Drogas de Colombia., Ministerio de Justicia y del Derecho., Ministerio de Educación Nacional., Ministerio de Salud y Protección social., \& Comisión Interamericana para el control del Abuso de Drogas CICAD. (2016). Estudio Nacional de consumo de sustancias psicoactivas en población escolar Colombia. Recuperado de: https://www.unodc.org/documents/colombia/2018/Junio/CO03142016_est udio_consumo_escolares_2016.pdf

Ochoa, C. (2013). Estudio sobre la toma de decisiones, el funcionamiento ejecutivo y la impulsividad en el juego patológico. (Tesis doctoral). Universidad de Barcelona. Barcelona, España. Recuperado de: https://dialnet.unirioja.es/servlet/tesis?codigo $=87954$

Oliva, A., \& Antolín, L. (2010). Cambios en el cerebro adolescente y conductas agresivas y de asunción de riesgos. Universidad de Sevilla. Recuperado de:

https://www.researchgate.net/publication/233546547_Cambios_en_el_cer ebro_adolescente_y_conductas_agresivas_y_de_asuncion_de_riesgosCh 
anges_in_the_adolescent_brain_and_aggressive_and_risk-

taking_behaviours

Organización Mundial de la Salud. (2016)._La dimensión de salud pública del problema mundial de las drogas. Recuperado de: https://apps.who.int/gb/ebwha/pdf_files/EB140/B140_29-sp.pdf

Organización Mundial de la Salud. (2011). La prueba de detección de consumo de alcohol, tabaco y sustancias (ASSIST) Manual para uso en la atención primaria.

Recuperado

de:

https://www.who.int/substance_abuse/activities/assist_screening_spanish. pdf

Organización Mundial de la Salud. (2005). Neurociencia del Consumo y Dependencia de Sustancias Psicoactivas. Recuperado de: https://www.who.int/substance_abuse/publications/neuroscience_spanish. pdf

Ospina, N., Pérez, C., Vargas, J., Cervántes, A., \& Rodríguez, M. (2017). Ganglios basales y conducta. Revista Mexicana de Neurociencia. 18 (6). 74-86. Recuperado de: http://revmexneuroci.com/wpcontent/uploads/2017/11/RevMexNeuroci_2017_186-74-86-R.pdf

Pino, M. \& Urrego, Y. (2013). La importancia de las funciones ejecutivas para el desarrollo de las competencias ciudadanas en el contexto educativo. Cultura, Educación y Sociedad 4(1), 9-20

Portellano, J. (2005). Introducción a la Neuropsicología. McGraw-Hill. México. Recuperado de: http://www.universidadcultural.com.mx/online/claroline/backends/downloa 
d.php?url=L05IdXJvcHNpY29sb2dpYV9JbnRyby4ucGRm\&cidReset=true \&cidReq=DLP7

Próspero, O. (2014). El cerebro adicto. Revista Ciencia. Recuperado de: https://www.revistaciencia.amc.edu.mx/images/revista/65_1/PDF/Cerebro Adicto.pdf

Regal-Domínguez, M., García de Vinuesa, A., Aguayo-González, F., LuqueSendra, A., \& González-Regalao Montero, E. (2017). Propuesta metodológica de neurodiseño de productos desde los marcadores somáticos de Damasio. Recuperado de: http://dspace.aeipro.com/xmlui/handle/123456789/378

Requena, C., Requena, P., Merino, P., \& Carmona, M. (2017). Toma de decisiones y aspectos emocionales en la vejez. La psicología hoy: retos, logros y perspectivas de futuro. El mundo del adulto y envejecimiento. https://doi.org/10.17060/ijodaep.2017.n2.v2.1076

Robinson, T \& Berridge, K. (2008). The incentive sensitization theory of addiction: some current issues. Phil. Trans. R. Soc. B. 363. 3137-3146. doi:10.1098/rstb.2008.0093

Rubiales, J., Urquijo, S., Said, A., \&Macbeth, G. (2017). Proceso de toma de decisiones en niños y adolescentes con TDAH: Revisión sistemática. Revista de Psicopatología y Psicología Clínica, 22(2), 139-155. Recuperado de: https://search-proquestcom.ucatolica.basesdedatosezproxy.com/docview/1951871860/fulltextPD F/B78B3EF2134A4FF9PQ/5?accountid=45660 
Ruiz, J. (2011). Neurociencia y adicción. Sociedad española de toxicomanías. Neurociencia $y$ adicción. Recuperado de: http://www.academia.edu/883020/Neurociencia_y_adicci\%C3\%B3n

Salvador, J., Mestas, L., Gordillo, F., Arana, J., Meilán, J., Pérez, E., \& Carro, J. (2010). Toma de decisiones en la anorexia nerviosa. Recuperado de: https://www.researchgate.net/publication/235411810_Toma_de_decisione s_en_la_anorexia_nerviosa

Sanz, M. (1996). Deterioro de la capacidad atencional como consecuencia del consumo de drogas: estudio neurocognitivo en politoxicomanos. (Tesis doctoral). Universidad Complutense de Madrid. Madrid, España.

Sarmiento- Rivera, L., \& Ríos- Flórez, J. (2017). Bases neurales de la toma de decisiones e implicación de las emociones en el proceso. Revista Chilena de Neuropsicología, 12 (2), 32-37. Recuperado de: http://www.redalyc.org/articulo.oa?id=179354005006

Scoppetta, O. (2015). El enfoque de la salud pública en la política de drogas. Recuperado de: http://www.odc.gov.co/Portals/1/dialogo_nacional/docs/posicion_de_gobie rno_hacia_UNGASS2016.pdf

Steinberg, L. (2008). A Social Neuroscience Perspective on Adolescent RiskTaking. doi: 10.1016/j.dr.2007.08.002

Squillace, M., Picón, J., \& Schmidt, V. (2015). Juego de Cartas, una tarea para la evaluación de toma de decisiones riesgosas: aportes a la validez ecológica y de constructo. Revista Neuropsicología Latinoamericana 7(3). 37-46. DOI:10.5579/rnl.2015.0240 
Trillos-Vélez, L., Tamayo-Barragán \& Artunduaga-Molina, P. (2020). Relación entre la Toma de Decisiones, el Estado de Ánimo en el Consumo de Spa en Jóvenes Universitarios. Universidad Cooperativa de Colombia. Recuperado de: https://repository.ucc.edu.co/bitstream/20.500.12494/17642/1/2020_toma_ decisiones_animo.pdf

Trujillo, N \& Pineda, D. (2008). Función ejecutiva en la investigación de los Trastornos del comportamiento del niño y del adolescente. Revista Neuropsicología, Neuropsiquiatría y Neurociencias. 5 (1). 77-94. Recuperado de: https://dialnet.unirioja.es/descarga/articulo/3987502.pdf.

Tirapu, J., García, A., Luna, P., Verdejo, A., \& Ríos, M. (2012). Corteza prefrontal, funciones ejecutivas y regulación de la conducta. ISBN 9788492931132, págs. 87-120. Recuperado de: https://webcache.googleusercontent.com/search?q=cache:ZIJAJhe8dkAJ: https://www.viguera.com/es/index.php\%3Fcontroller\%3Dattachment\%26id _attachment\%3D14+\&cd=1\&hl=es\&ct=clnk\&gl=co

Valdés, J., \& Torrealba, F. (2005). La corteza prefrontal medial controla el alerta conductual y vegetativo. Implicancias en desórdenes de la conducta. Revista Chilena de Neuro-Psiquiatría. 44(3). 195-204. Recuperado de: https://scielo.conicyt.cl/pdf/rchnp/v44n3/art05.pdf

Vargas- Trujillo, E., Henao, J., \& González, C. (2007). Toma de decisiones sexuales y reproductivas en la adolescencia. Acta Colombiana de Psicología, 10 (1), 49-63. Recuperado de: http://www.redalyc.org/articulo.oa?id=79810106 
Verdejo, A. (2006). Funciones ejecutivas y toma de decisiones en drogodependientes. Rendimiento neuropsicológico y funcionamiento cerebral. (Tesis doctoral). Universidad de Granada. Granada, España.

Verdejo, A., \& Bechara, A. (2010). Neuropsicología de las funciones ejecutivas. Psicothema. 22(2), 227-235. Recuperado de: https://www.redalyc.org/pdf/727/72712496009.pdf

Verdejo, A., \& Bechara, A. (2009). Un marcador somático de la adicción. Recuperado de: http://www.adolescenciaalape.com/sites/www.adolescenciaalape.com/files /Marcador.somatico\%20de\%20la\%20Adicci\%C3\%B3n.pdf

Verdejo, A., \& Pérez, M. (2006). Funciones ejecutivas y toma de decisiones en drogodependientes: Rendimiento Neuropsicológico y Funcionamiento Cerebral. Universidad de Granada. Recuperado de: http://digibug.ugr.es/bitstream/handle/10481/901/16052882.pdf?sequence $=1$

Verdejo-García, A.., Aguilar de Arcos, F., \& Pérez-García, M. (2004). Alteraciones de los procesos de toma de decisiones vinculados al córtex prefrontal ventromedial en pacientes drogodependientes. Revista Neurología, 38, (7), 601-606.

Villa, M., Navarro, M., \& Villaseñor, T. (2017). Neuropsicología clínica hospitalaria. México: Manual Moderno.

Villalba, E., \& Verdejo, A. (2012). Procesamiento emocional, interocepción y funciones ejecutivas en policonsumidores de drogas en tratamiento. Trastornos adictivos, 14 (1), 10-20. Recuperado de: http://apps.elsevier.es/watermark/ctl_servlet?_f=10\&pident_articulo=9014 
0317\&pident_usuario=0\&pcontactid=\&pident_revista $=182 \&$ ty $=61 \&$ accion $=$ L\&or

igen=elsevier\&web=www.elsevier.es\&lan=es\&fichero=182v14n01a901403 17pdf001.pdf

Volkow, N. (2014). Las drogas, el cerebro y el comportamiento. La ciencia de la adicción. https://d14rmgtrwzf5a.cloudfront.net/sites/default/files/soa_sp_2014.pdf

Yip, J., Stein, D., Côté, S., \& Carney, D. (2019). Follow Your Gut? Emotional Intelligence Moderates the Association Between Physiologically Measured Somatic Markers and Risk-Taking. Emotion. Advance online publication. http://dx.doi.org/10.1037/emo0000561 


\section{Apéndices}

Apéndice A. Formato de Historia Clínica

\section{FORMATO HISTORIA CLÍNICA}

\begin{tabular}{|l|}
\hline \\
\hline Nombres y apellidos: \\
Documento de identificación: \\
Sexo: \\
Lugar de nacimiento: \\
Fecha de nacimiento: dd/ mm/ aaaa de identificación \\
Lugar de residencia: \\
Teléfono: \\
Institución educativa: \\
Grado escolar: \\
Nombre del representante legal: \\
Teléfono: \\
Fecha de evaluación: $\mathrm{dd} / \mathrm{mm} /$ aaaa
\end{tabular}


Marque con una $\mathrm{X}$ si presenta alguna de las siguientes condiciones

Problemas de lenguaje

Déficit sensorial

Parálisis cerebral

Epilepsia

Déficit de atención con o sin hiperactividad

Problemas de coordinación motora

Dificultades de aprendizaje

Trastorno del desarrollo intelectual

Enfermedad psiquiátrica

Traumatismo craneoencefálico

Drogadicción/ Alcoholismo

Problemas de comportamiento 


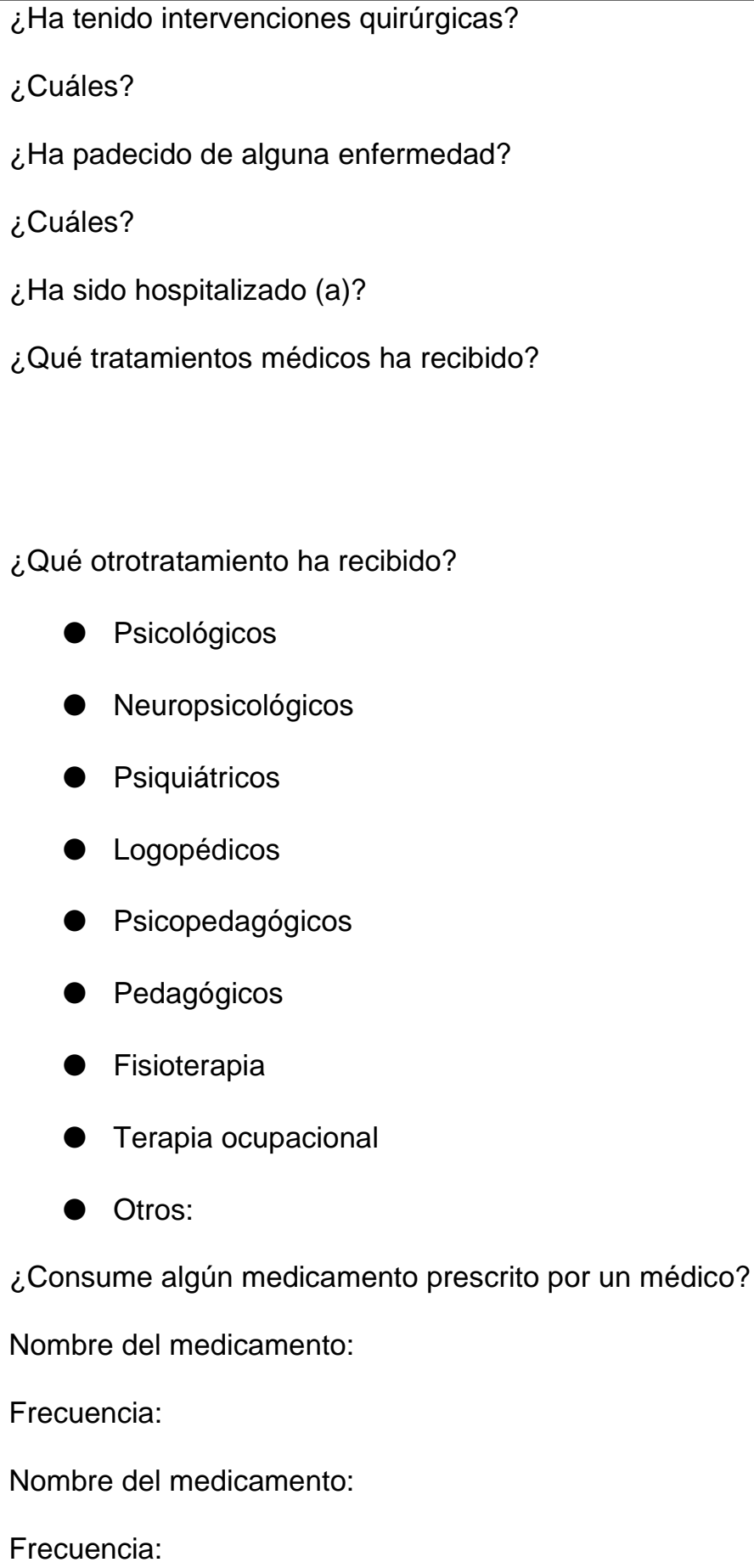




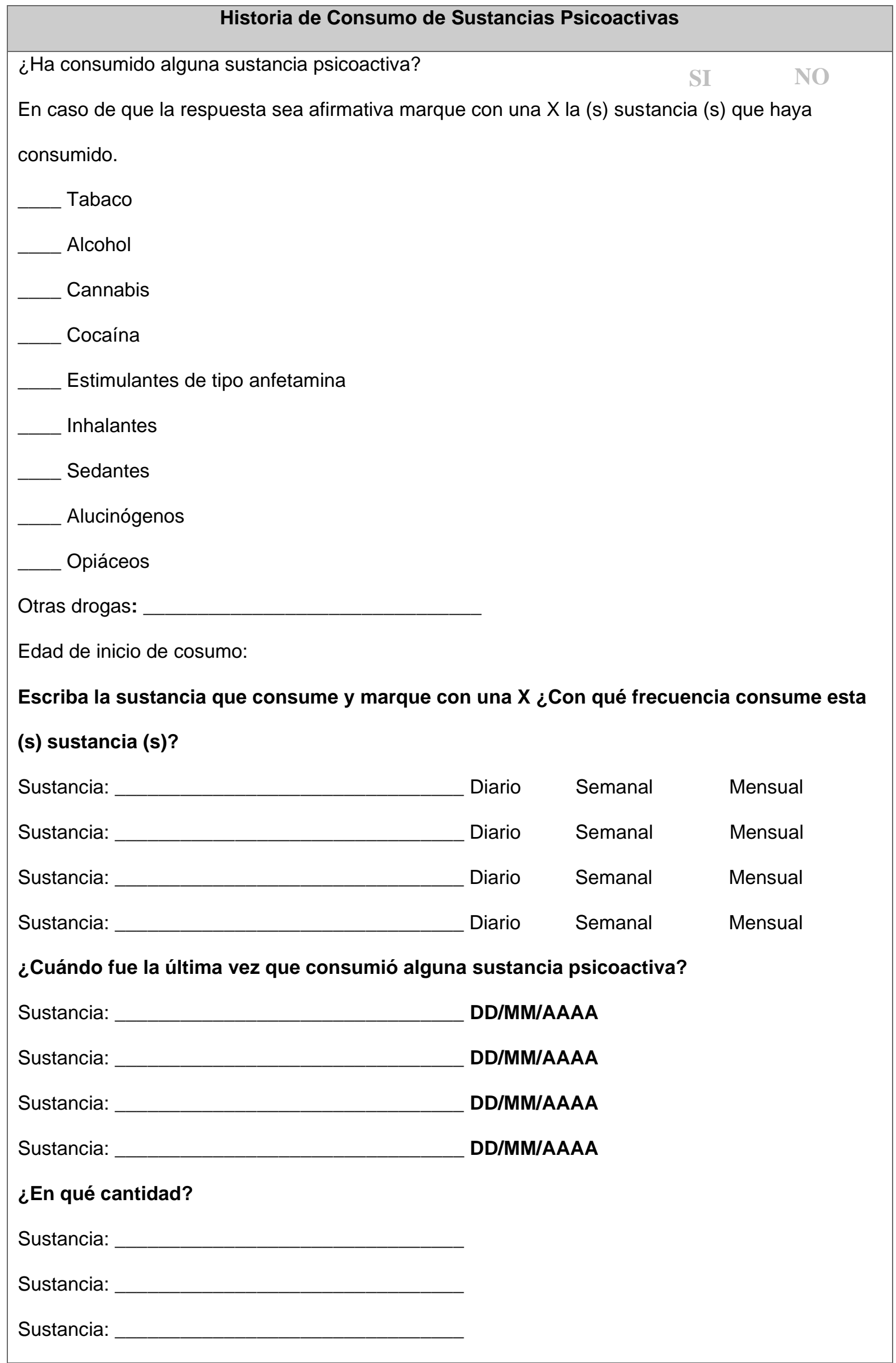


Sustancia:

Apéndice B. Prueba de detección de alcohol, tabaco y sustancias (ASSIST V 3.1) 


\section{Apéndice $A$}

La prueba de detección de consumo de alcohol, tabaco y sustancias (ASSIST v3.1)

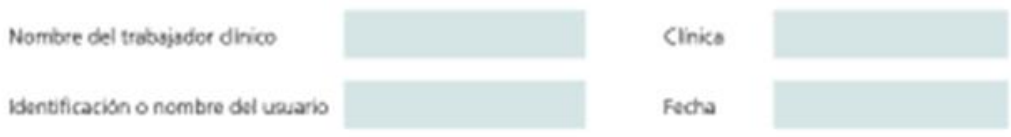

Introducción (léasela al usuario o adáptela a las circunstancias locales)*

Las siguientes preguntas se refieren a su experiencia sabre el consumo de alcohol tabaco y ouras sustanclas a lo largo de la wida y en los uitimos tres mesex. Estas scrtancias se pueden fumar, ingeri: inhalar o inyectar (muestre la tarjeta de respuestas).

Abunas de estas sustanolas pueden ser recetadas par un medico (como las anfetaminas los sedantes, los anaigetsicas). Para esta entrevista, no se registrarán las medicinas que han sido recetadas por su medica. Sin embarga, si ha tomado esas medichas por otros mocivos que los recetadas, o las ha tomado mis a menudo o en dosis mis altas que las recetadas, digameio

Aungue tambien nos interesa conocer las diferentes drogas ilicitas que ha consumido, tenga la segunidad de que esa informxción serb estrictamente confidencial.

Antes de hacer las preguntas, entregue al usuario la tarjeta de respuestas.

\begin{tabular}{|c|c|c|c|}
\hline \multicolumn{2}{|l|}{ a Tabeco (ógariles, tabsco de mascar, purcs, etc) } & No & Si \\
\hline \multicolumn{2}{|l|}{ b Bebidas akoholicas (cerwaz, vhos, lcores, ex.) } & No & Si \\
\hline \multicolumn{2}{|l|}{ c Camabs (marhuans, mota, kierba hachis, etc) } & No & si \\
\hline \multicolumn{2}{|l|}{ d Cocaina (cosa oack, etc) } & No & Si \\
\hline \multicolumn{2}{|c|}{ e Estimulartes de tipo anfetaming (speed, antetaminas, extasis etc) } & No & Si \\
\hline \multicolumn{2}{|c|}{ If Inhalartes \{0vido ritrosa, pegamenta, gavolina, solvente para pinsura, etc) } & No & si \\
\hline \multicolumn{2}{|c|}{ g Sedantes o pastilas para dormir (diazepam a'prazolam, fluritrazepam midazolam, eec) } & No & si \\
\hline \multicolumn{2}{|c|}{ h Alukinógenos (LSO, boides, hanges, betamina, etc) } & No & 51 \\
\hline \multicolumn{2}{|c|}{ i Opibseos theroho, morfina metadons, buprenorfina codehs, eK. J } & No & $5 i$ \\
\hline \multicolumn{2}{|c|}{ I Otrax especfique: } & No & S1 \\
\hline \multirow[t]{2}{*}{$\begin{array}{l}\text { S vodas las respuestas fueron nogytivas pregunte: } \\
\text { "iNi siquera cuando estaba en la esoweta?" }\end{array}$} & \multicolumn{3}{|c|}{$\begin{array}{l}\text { Si la respussta es negativa para todas las progen- } \\
\text { tas, decenga la entrevista. }\end{array}$} \\
\hline & \multicolumn{3}{|c|}{$\begin{array}{l}\text { Si la respussta es afrmutiva a cualquiera de estas } \\
\text { preguntas, hops la pregunta } 2 \text { para coda sustancis } \\
\text { que se hyya consumido alguns vez. }\end{array}$} \\
\hline
\end{tabular}

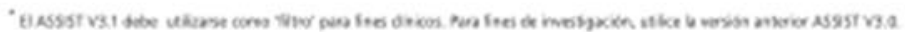




\begin{tabular}{|c|c|c|c|c|c|}
\hline $\begin{array}{l}\text { PREGUNTA } 2 \text { I En los ditimos tres meses, ¿con qué } \\
\text { frecuencia ha consumido las sustancias que menciono } \\
\text { (primera droga, segunda droga, etc.)? }\end{array}$ & $\frac{3}{2}$ & $\begin{array}{l}\frac{8}{8} \\
\frac{8}{8} \\
8 \\
\frac{8}{5}\end{array}$ & $\frac{\frac{z}{2}}{\frac{z}{y}}$ & $\frac{\frac{z}{z}}{\frac{z}{z}}$ & 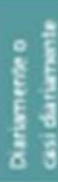 \\
\hline a Tabsco (ógarrilos, tabaco de mascar, puros, etc) & 0 & 2 & 3 & 4 & 6 \\
\hline b Bebidas akoholicas (cervezs, vinos, ficores, etc) & 0 & 2 & 3 & 4 & 6 \\
\hline c Camabis (manhuana mota, hierba, hachis, stc) & 0 & 2 & 3 & 4 & 6 \\
\hline d Cocaina (coca, crack, etc) & 0 & 2 & 3 & 4 & 6 \\
\hline e Estimulantes de tipo anfetarnins fspeed, anfetarrinss, bxtasis, etc) & 0 & 2 & 3 & 4 & 6 \\
\hline $\begin{array}{l}\text { f Inhalantes (6ovido ritrosa pegamenta, gasolna solvente pars pinturs. } \\
\text { etc) }\end{array}$ & 0 & 2 & 3 & 4 & 6 \\
\hline $\begin{array}{l}9 \text { Sedantes o pastilas pars dormir (diazepam, aprazolam, } \\
\text { flunitracepon midazolam, etc) }\end{array}$ & 0 & 2 & 3 & 4 & 6 \\
\hline h Alucinogenos (LSD, aciblos, hangok, betamina, etc.) & 0 & 2 & 3 & 4 & 6 \\
\hline I Opisceos (harcina, mortina metadona, buprenerfra, codsina, ecc) & 0 & 2 & 3 & 4 & 6 \\
\hline j Otra, expecifiax: & 0 & 2 & 3 & 4 & 6 \\
\hline \multicolumn{6}{|c|}{$\begin{array}{l}\text { Si la respuesta es "Nunca" a todas las secciones de la pregunta 2, pase a la pregunts } 6 . \\
\text { Si se ha coroumido abyna sustancis de la pregunta } 2 \text { en las Ǵltimos tres meses, contince con las preguntas } \\
3,4 \text { y } 5 \text { para cada astancia consumida. }\end{array}$} \\
\hline
\end{tabular}

\begin{tabular}{|c|c|c|c|c|c|}
\hline $\begin{array}{l}\text { PAEGUNTA } 3 \text { I En los ditimos tres meses, ¿con qub } \\
\text { frecuencia ha sentido un fuerte deseo o ansias de } \\
\text { consumir (primera droga, segunda droga, etc.)? }\end{array}$ & $\frac{3}{2}$ & $\begin{array}{l}\frac{7}{8} \\
\frac{8}{8} \\
\frac{8}{3} \\
\frac{8}{3}\end{array}$ & $\frac{\frac{8}{2}}{\frac{1}{2}}$ & $\frac{\frac{3}{2}}{\frac{5}{2}}$ & 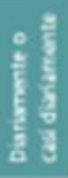 \\
\hline a Tabsco (cigsrrilos, tabsco de mascar, puros, etc) & 0 & 3 & 4 & 5 & 6 \\
\hline b Bebidas alcoholicas (cerweza, vinos, lkores, etc.) & 0 & 3 & 4 & 5 & 6 \\
\hline c Cannabis (marithuna, mota, hierbs, hachis, etc) & 0 & 3 & 4 & 5 & 6 \\
\hline d Cocsins (coca, crsck, ek) & 0 & 3 & 4 & 5 & 6 \\
\hline e Estimulantes de tipo anfecamina (speed, anfetaminas, bxtasia etc.) & 0 & 3 & 4 & 5 & 6 \\
\hline $\begin{array}{l}\text { f Inhalantes (6oido ritrosa, pegamento, gssoins sokente para } \\
\text { pirsura, etc.) }\end{array}$ & 0 & 3 & 4 & 5 & 6 \\
\hline $\begin{array}{l}9 \text { Sedarhes o pastilas para dormir (diacepam abrazolam, } \\
\text { flunibazopam midazolam etc) }\end{array}$ & 0 & 3 & 4 & 5 & 6 \\
\hline h Alxindgenos (LSD, bcides, honges, ketemins, ek] & 0 & 3 & 4 & 5 & 6 \\
\hline I Opliceos (heroina, morfina, metadona, buprenorina, codeha, etc) & 0 & 3 & 4 & 5 & 6 \\
\hline j Oras, especifique: & 0 & 3 & 4 & 5 & 6 \\
\hline
\end{tabular}




\begin{tabular}{|c|c|c|c|c|c|}
\hline $\begin{array}{l}\text { PREGUNTA } 2 \text { I En los ditimos tres meses, ¿con qub } \\
\text { frecuencia ha consumido las sustancias que mencion' } \\
\text { (primera droga, segunda droga, etc.)? }\end{array}$ & $\frac{8}{2}$ & $\begin{array}{l}8 \\
8 \\
8 \\
8 \\
8 \\
5 \\
8\end{array}$ & $\frac{\frac{z}{v}}{\frac{z}{z}}$ & $\frac{\frac{z}{z}}{\frac{z}{2}}$ & 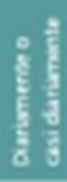 \\
\hline a Tabsco (ógarrilos, taboco de mascer, puros, etc) & 0 & 2 & 3 & 4 & 6 \\
\hline b Bebidas alocholicas (cervezs, inos, ficores, etc) & 0 & 2 & 3 & 4 & 6 \\
\hline c Camabis (manhuana mota, hierba, hachis, stc) & 0 & 2 & 3 & 4 & 6 \\
\hline d Cocaina (coca, crack, etc.) & 0 & 2 & 3 & 4 & 6 \\
\hline e Estimulentes de tioo anfetamins (speed, anfetaminss, extasis, etc) & 0 & 2 & 3 & 4 & 6 \\
\hline $\begin{array}{l}\text { I Inhalantes (boido ritrosa pegamenta, gasolna solvente pars pinturs. } \\
\text { etc) }\end{array}$ & 0 & 2 & 3 & 4 & 6 \\
\hline $\begin{array}{l}9 \text { Sedantes o pastilas pars dormir (diazepam, aprazolam, } \\
\text { flunitracepan midazolam, etc) }\end{array}$ & 0 & 2 & 3 & 4 & 6 \\
\hline h Alucinogonos (LSD, sciblos, hongos, betamina, etc.) & 0 & 2 & 3 & 4 & 6 \\
\hline I Opisceos (hercina, mortina metadona, buprenorfrna, codsina, ecc) & 0 & 2 & 3 & 4 & 6 \\
\hline j Otras, expecifiax: & 0 & 2 & 3 & 4 & 6 \\
\hline \multicolumn{6}{|c|}{ 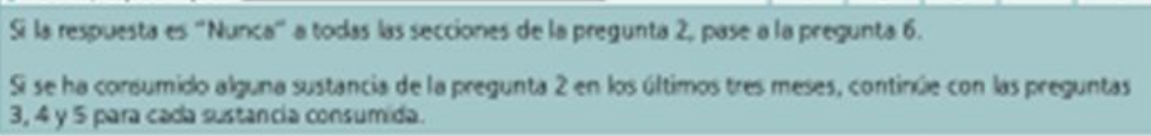 } \\
\hline
\end{tabular}

\begin{tabular}{|c|c|c|c|c|c|}
\hline $\begin{array}{l}\text { PREGUNTA } 3 \text { I En los ditimos tres meses, ¿con qub } \\
\text { frecuencia ha sentido un fuerte deseo o ansias de } \\
\text { consumir (primera droga, segunda droga, etc.)? }\end{array}$ & $\frac{3}{2}$ & $\begin{array}{l}\frac{8}{8} \\
\frac{8}{8} \\
8 \\
8 \\
\frac{8}{5}\end{array}$ & $\frac{\frac{z}{2}}{\frac{y}{2}}$ & $\frac{\frac{3}{2}}{\frac{z}{2}}$ & 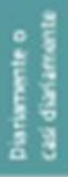 \\
\hline - Tabaco (ćgarrillos, tabsco de mascar, puros, etc) & 0 & 3 & 4 & 5 & 6 \\
\hline b Bebidas alcoholicas (cerwaz, vinos, lkores, etc.) & 0 & 3 & 4 & 5 & 6 \\
\hline (Cannabis (marithuana, mota, hierbs, hachis, etc) & 0 & 3 & 4 & 5 & 6 \\
\hline d Cocsins (coca, crock, ex) & 0 & 3 & 4 & 5 & 6 \\
\hline - Estimulantes de tipo anfecamina \{speed, anfetaminas, Lxtasia etc) & 0 & 3 & 4 & 5 & 6 \\
\hline $\begin{array}{l}\text { I Inhalantes (coido ritrosa, pegamento, gssoina sokente para } \\
\text { pirsura, etc.) }\end{array}$ & 0 & 3 & 4 & 5 & 6 \\
\hline $\begin{array}{l}9 \text { Sedartes o pastilas para dormir (diacepam, aprazolam, } \\
\text { flunitrazopam midazolam etc) }\end{array}$ & 0 & 3 & 4 & 5 & 6 \\
\hline h Alxindgenos (LSD, bcidos, honges, ketamins, eKk] & 0 & 3 & 4 & 5 & 6 \\
\hline 1 Oplaceos ohercina, morfina, metasona, buprenorina, codeha, etc) & 0 & 3 & 4 & 5 & 6 \\
\hline f Orax, expecitoue: & 0 & 3 & 4 & 5 & 6 \\
\hline
\end{tabular}




\begin{tabular}{|c|c|c|c|}
\hline $\begin{array}{l}\text { PREGUNTA } 6 \text { I ¿Un amigo, un famillar o algulen más alguna vez } \\
\text { ha mostrado preocupación por sus híbitos de consumo de (primera } \\
\text { droga, segunda droga, etc.)? }\end{array}$ & $\frac{8}{2}$ & 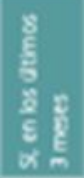 & $\begin{array}{l}\frac{8}{5} \\
8 \\
8 \\
8 \\
8 \\
8 \\
05\end{array}$ \\
\hline a Tabaco (digarrlibs, tabaco de macar, puros, etc) & 0 & 6 & 3 \\
\hline b Bebides alcoholicas (cerveza, vinos, licores, elc) & 0 & 6 & 3 \\
\hline c Cannabis (markwana, mota, hierba, hachis, etc) & 0 & 6 & 3 \\
\hline d Cocaina (coca, crack, exc) & 0 & 6 & 3 \\
\hline e Estmulantes de tipo anferamina (speed anletarninas, extasio, etc.) & 0 & 6 & 3 \\
\hline It Inhalantes (owido ritroca, prgamento, gasolina, solvente para pintura, etc) & 0 & 6 & 3 \\
\hline $\begin{array}{l}9 \text { Sedartes o pastilas para dormi (dazopam akrazolam, flavitrazopam, } \\
\text { midazolam, etc) }\end{array}$ & 0 & 6 & 3 \\
\hline h Alsoinogenos (ISD, sodes, honges, ketamina, ex.) & 0 & 6 & 3 \\
\hline i (Cpibceos (heroins, morfina, metadona, buprenorfina, codeha, etc) & 0 & 6 & 3 \\
\hline J Ora, espectique: & 0 & 6 & 3 \\
\hline
\end{tabular}

\begin{tabular}{|c|c|c|c|}
\hline $\begin{array}{l}\text { PREGUNTA } 7 \text { I LHa intentado alguna vez reducir o eliminar el } \\
\text { consumo de (primera droga, segunda droga) y no lo ha logrado? }\end{array}$ & $\begin{array}{l}\frac{3}{5} \\
\frac{5}{2} \\
\frac{\delta}{z}\end{array}$ & $\begin{array}{l}\frac{8}{8} \\
\frac{8}{5} \\
\frac{8}{5} \\
\frac{8}{5} \\
\frac{8}{E} \\
\frac{1}{E}\end{array}$ & 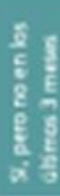 \\
\hline a Tabsco (ógsmilos, tabsco de mascar, puros, etc) & 0 & 6 & 3 \\
\hline b Bebides dicoholicas (cervezo, vinos, likores, etc.) & 0 & 6 & 3 \\
\hline c Cannabis (markuana, mota, hierba, hactis, etc) & 0 & 6 & 3 \\
\hline d Cocsins (coca, cesck, ek) & 0 & 6 & 3 \\
\hline - Estimulantes de tipo anteramina ispeed anfetaminas, extasio, etc] & 0 & 6 & 3 \\
\hline f Imalantes (Covdo ritrosa, prgamsnto, gasolina, solvente para pintura, etc) & 0 & 6 & 3 \\
\hline $\begin{array}{l}9 \text { Sedartes o pastilas pars dormir (dacepam aprazolam, flaritrazepam, } \\
\text { midazolam, etc) }\end{array}$ & 0 & 6 & 3 \\
\hline h Alwoindgenes (LSD, bides, honges, ketarrins, eX.) & 0 & 6 & 3 \\
\hline i (Cpibceos theroins, morfina, metadona, buprenorfina, codeha, etc) & 0 & 6 & 3 \\
\hline J Ora, espectique: & 0 & 6 & 3 \\
\hline
\end{tabular}




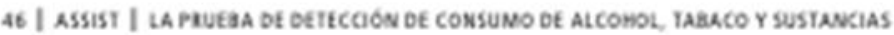

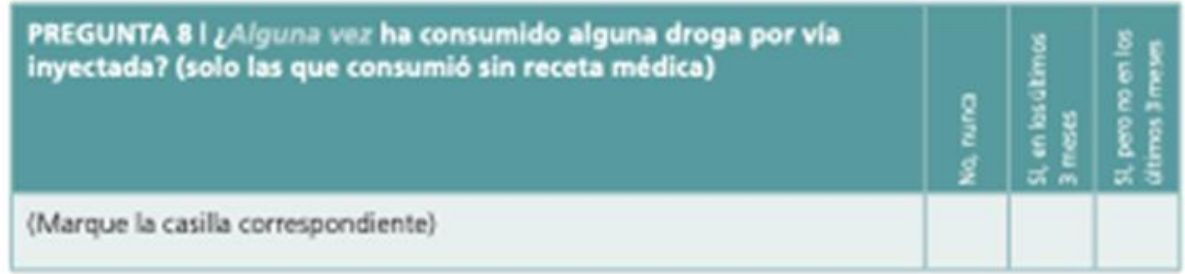

\section{NOTA IMIPORTANTE}

A los usuarios que se han inyectado drogas en los cltimos tres meses se les dobe pregartar acerca de as habitos de injoccion durante este periodo para determinar sus niveles de rissgo y al mejor curso de intervenoión.

\section{Hábitos de inyectarse}

Cuatro dias por mes, en promedio, durante los ülimas tres meses o menos

Mas de cuatro dias por mes, en promedio, durante los últimos tres meses
Lineamientos de intervención

Intervención breve que incluye los riesgos de la tarjeta de inyecoón

Evaluadon adicional y tratamiento más intensivo

Cómo calcular la puntuación de consumo de una sustancia especifica

Para cada sustancia (rotulada 'a' a la 17) sume las puntuadones de las preguntas 2 a la 7 . No incluya los resultados de la pregunta 1 o de la pregunta 8 en esta puntuación. Por ejemplo, una puntusción para cannabis se cakularia como: $\mathbf{P 2 C}+\mathbf{P 3 C}+\mathbf{P 4 C}+\mathbf{P 5 C}+\mathbf{P 6 C}+\mathbf{P 7 C}$.

Observe que la pregunta 5 para tabaco no esta codificada, y se calcula como: P2a + P3a + P4a + P6a + P7a. 


\begin{tabular}{|c|c|c|c|c|}
\hline \multicolumn{5}{|c|}{ El tipo de intervención se determins por la puntusción de consumo de sustancias especificas } \\
\hline & $\begin{array}{l}\text { Registrar la } \\
\text { puntuadón } \\
\text { para cada } \\
\text { sustancia }\end{array}$ & $\begin{array}{l}\text { No requiere } \\
\text { Intervencion }\end{array}$ & $\begin{array}{l}\text { Recibir } \\
\text { Intervencion } \\
\text { breve }\end{array}$ & $\begin{array}{l}\text { Tratamiento } \\
\text { más intensivo }\end{array}$ \\
\hline a Tabsco & & $0-3$ & $4-26$ & $27+$ \\
\hline b Alcohd & & $0-10$ & $11-26$ & $27+$ \\
\hline c Connabis & & $0-3$ & $4-26$ & $27+$ \\
\hline d Cocaina & & $0-3$ & $4-26$ & $27+$ \\
\hline $\begin{array}{l}\text { - Estimulentes de tipo } \\
\text { anfetamina }\end{array}$ & & $0-3$ & $4-26$ & $27+$ \\
\hline$f$ Inhalgntes & & $0-3$ & $4-26$ & $27+$ \\
\hline 9 Sedantes & & $0-3$ & $4-26$ & $27+$ \\
\hline h Alsénogenos & & $0-3$ & $4-26$ & $27+$ \\
\hline i Cpribceos & & $0-3$ & $4-26$ & $27+$ \\
\hline f Otras drogas & & $0-3$ & $4-26$ & $27+$ \\
\hline
\end{tabular}




\section{Apéndice B}

\section{Tarjeta de respuestas del ASSIST v3.1}

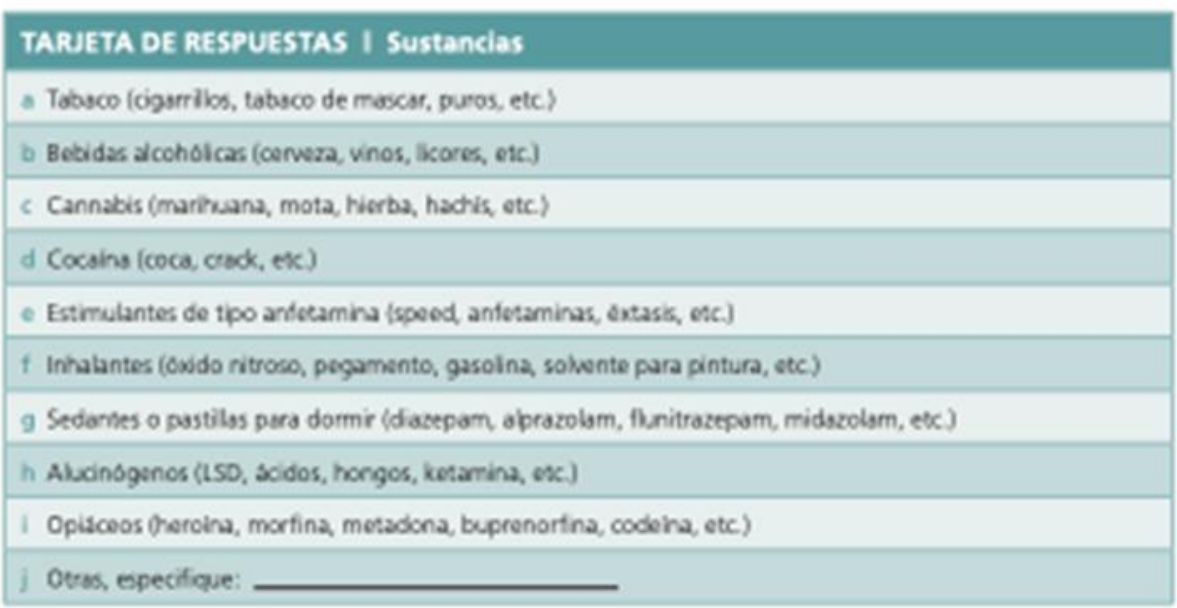

\section{TARIETA DE RESPUESTAS I Respuestas de frecuencia}

Respuestas

Oltimos tres meses (preguntas 2 a 5 del ASSIST)

I Nunca: no se ho consumido en los tres uitimos mescs.

I Una o dos reces: de una a dos veces en los Utimos tres mases.

I Mensualmente: promedio de una a tres veces al mes en los Cltimos tres meses.

I Semanalmente: de una a cuatro veces a la semana.

I Diariamente o casi diariamente: de dinco a siete veces a la stmans.
Frecuencia

A lo largo de la vida (preguntas 6 a 8 del ASSIST)

1 No, nunca.

I Si pero no en los últimos tres meses.

I Si, en los Giltimos tres meses. 


\section{Apéndice C}

\section{Tarjeta de reporte de retroalimentación del ASSIST v3.1}

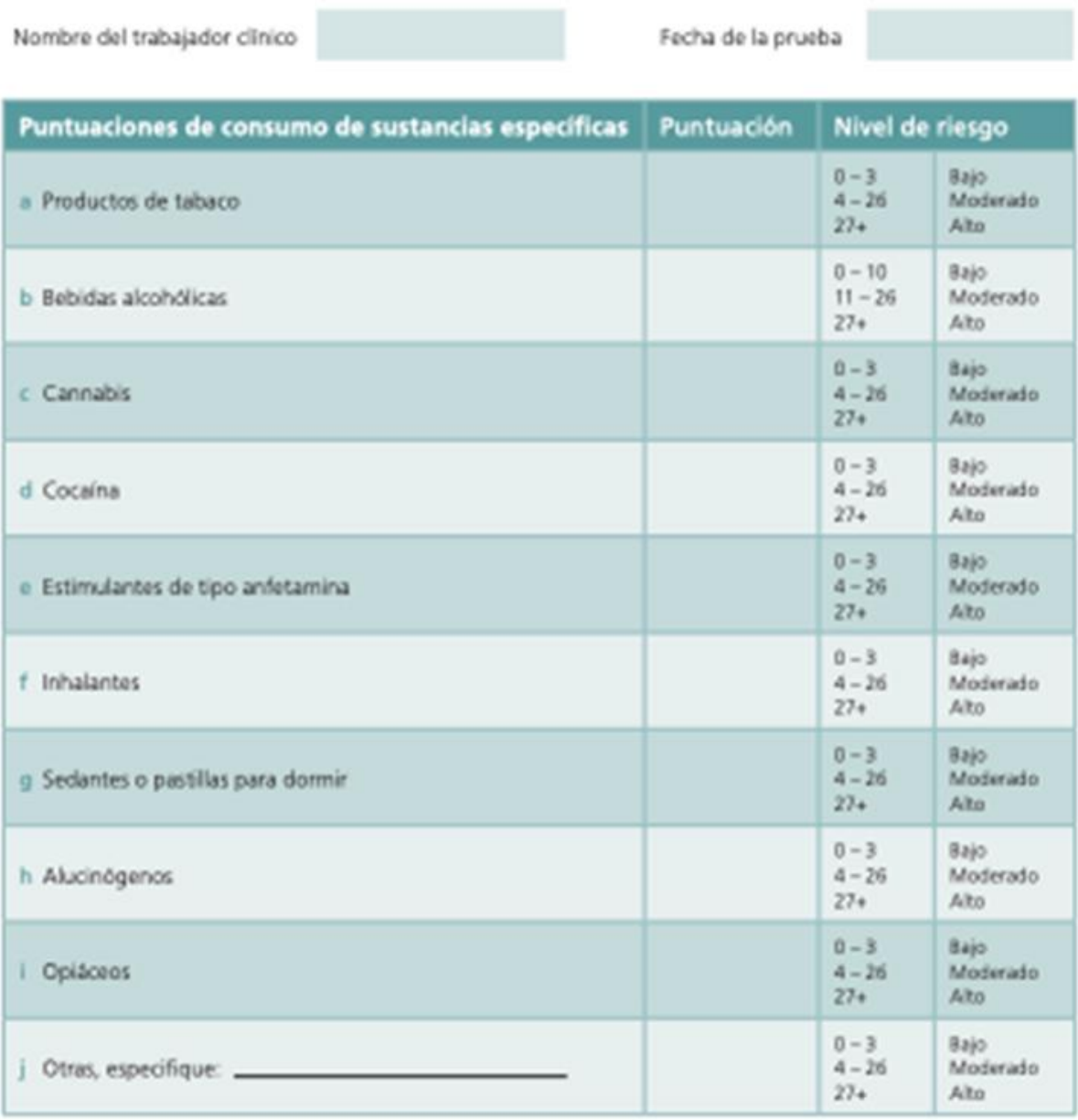

\section{¿Qué significan sus puntuaciones?}

Bafo: Usted corre un niesgo inferior de terer problemas de salud y otros problemas por as habinos actuales de consumo de sustandas.

Moderado: Usted corre un riesgo moderado de tener problemas de salud y otros problemas por sus habitos actuales de consumo de sustandas.

Alto: Usted corre un rivspo ato de toner problemas craves (de salud, sodalos, cocnomicos, legalus, un 9.5 relaciones) a corsecuencis de sus habitos actuales de coroumo y es probable que ses dependerte. 


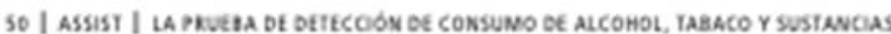

\section{¿Le preocupan sus habitos de consumo de sustancias?}

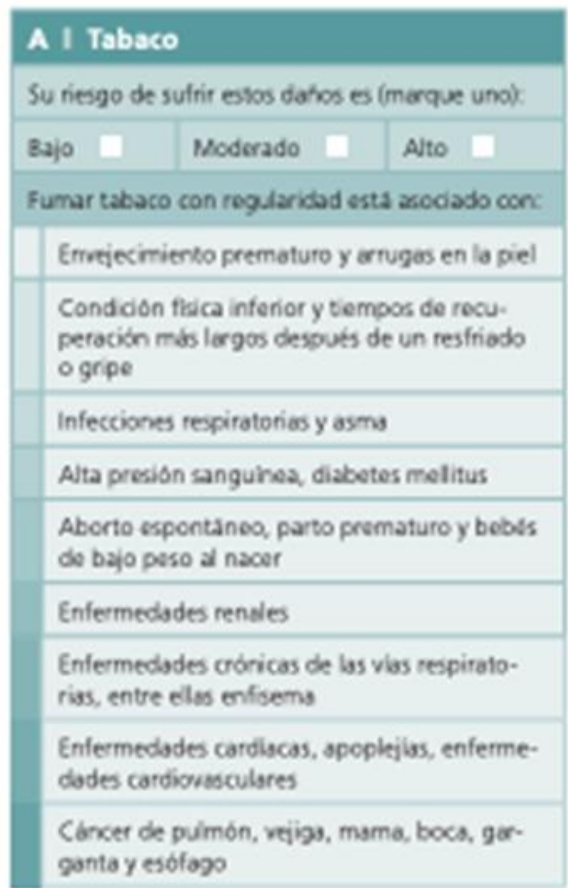

\begin{tabular}{|c|c|c|}
\hline \multicolumn{3}{|c|}{ Su riesgo de sufrir estos danos es (marque uno): } \\
\hline Bajo & Moderado & Alto \\
\hline \multicolumn{3}{|c|}{$\begin{array}{l}\text { El consumo ercesivo de alcohol con regularidad } \\
\text { estb asociado con: }\end{array}$} \\
\hline \multicolumn{3}{|c|}{$\begin{array}{l}\text { Reacas, conducta violenta y agresiba acd. } \\
\text { dentes y lesiones, njused y rómito }\end{array}$} \\
\hline \multicolumn{3}{|c|}{$\begin{array}{l}\text { Dismiruxoon en el desampero serual, invejec } \\
\text { imiento permaturo }\end{array}$} \\
\hline \multicolumn{3}{|c|}{$\begin{array}{l}\text { Problsmas digsstivos, Ulceras, inflamacion del } \\
\text { páncreas, alta presión sanguines }\end{array}$} \\
\hline \multicolumn{3}{|c|}{$\begin{array}{l}\text { Ansiodad y depresion, dificultades on las } \\
\text { relociones personsles, problemas económicos } \\
\text { y laborales }\end{array}$} \\
\hline \multicolumn{3}{|c|}{$\begin{array}{l}\text { Dificultad pars recordar cosas y resoluer } \\
\text { problemas }\end{array}$} \\
\hline \multicolumn{3}{|c|}{$\begin{array}{l}\text { Deformicades y daro cerebral en los bobss do } \\
\text { mujeres embersadas }\end{array}$} \\
\hline \multicolumn{3}{|c|}{$\begin{array}{l}\text { Dano cerobral pormanente que llova a la } \\
\text { perdids de memoris, defióts cognitivos y } \\
\text { descrivntacion }\end{array}$} \\
\hline \multicolumn{3}{|c|}{ Apopleja, dafo musculer y en los nervios } \\
\hline \multicolumn{3}{|c|}{ Enformsdad del rigado y el pancreas } \\
\hline \multicolumn{3}{|c|}{ Cancer de boca, garganta y mama } \\
\hline Suiodio & & \\
\hline
\end{tabular}




\begin{tabular}{|c|c|c|}
\hline \multicolumn{3}{|c|}{$\begin{array}{l}\text { Su rissgo de experimsntar estos danos es imarque } \\
\text { unok }\end{array}$} \\
\hline 8ajo & Moderado & Alto \\
\hline \multicolumn{3}{|c|}{ El consumo reglar de cannabis ests arodado con: } \\
\hline \multicolumn{3}{|c|}{ Problemas de atencion y motirsoion } \\
\hline \multicolumn{3}{|c|}{ Anaieded, paranoia, panica, depresion } \\
\hline \multicolumn{3}{|c|}{$\begin{array}{l}\text { Disminucion de la memoria y de la capadidad } \\
\text { para resolver problemas }\end{array}$} \\
\hline \multicolumn{3}{|c|}{ Fresión sangines alts } \\
\hline \multicolumn{3}{|c|}{ Asma y beonquitis } \\
\hline \multicolumn{3}{|c|}{$\begin{array}{l}\text { hicosis, en particular en personas con historid } \\
\text { personal o familar de esquiaotreria }\end{array}$} \\
\hline \multicolumn{3}{|c|}{$\begin{array}{l}\text { Enfermedades cardiscas y entermedad } \\
\text { pumoner obstructing coónica }\end{array}$} \\
\hline \multicolumn{3}{|c|}{$\begin{array}{l}\text { Cancer de las vias respiratorias supericres y de } \\
\text { garganta }\end{array}$} \\
\hline
\end{tabular}

\section{I Cocaina}

Su riesgo de experimentar estos dahos es imarque uno):

\begin{tabular}{|c|c|c|}
\hline 8ajo & Moderado & Alto \\
\hline \multicolumn{3}{|c|}{ El corcumo regular de cocaina esta asociado con: } \\
\hline \multicolumn{3}{|c|}{$\begin{array}{l}\text { Dificultad pars dormit, sceleramiento de } \\
\text { corazón, dolores de cabeza perdids de peso }\end{array}$} \\
\hline \multicolumn{3}{|c|}{$\begin{array}{l}\text { Alecargamiento, hormiguea, piel hümeda, } \\
\text { rascarse o arrancarse la pid }\end{array}$} \\
\hline \multicolumn{3}{|c|}{$\begin{array}{l}\text { Ansias o desso intanso, estres por el estilo de } \\
\text { vids }\end{array}$} \\
\hline \multicolumn{3}{|c|}{ Accidentes y lesiones, problemss económicos } \\
\hline \multicolumn{3}{|c|}{$\begin{array}{l}\text { Cambios del estado de brimo: arsiedad, } \\
\text { depresion, mantas }\end{array}$} \\
\hline \multicolumn{3}{|c|}{$\begin{array}{l}\text { Paranola, porsamientos irradonales, dificultad } \\
\text { para recordar cosas }\end{array}$} \\
\hline \multicolumn{3}{|c|}{ Condxta agresiva y violenta } \\
\hline \multicolumn{3}{|c|}{$\begin{array}{l}\text { Psicosis despuxis del coreumo repetido de altas } \\
\text { dosis }\end{array}$} \\
\hline \multicolumn{3}{|c|}{$\begin{array}{l}\text { Muerte repentina por endormsdades } \\
\text { cardionsoulares agudas }\end{array}$} \\
\hline
\end{tabular}

\begin{tabular}{|c|c|c|}
\hline $\begin{array}{l}\text { su riesgo } \\
\text { unat }\end{array}$ & perimentar esto & hos es imarque \\
\hline Bsio & Modersobo & Ato \\
\hline $\begin{array}{l}\text { El consam: } \\
\text { amina est: }\end{array}$ & $\begin{array}{l}\text { gular de estimul } \\
\text { ociado con: }\end{array}$ & s de tipo anfet. \\
\hline $\begin{array}{l}\text { Difioults: } \\
\text { destistro } \\
\text { infecoos }\end{array}$ & $\begin{array}{l}\text { ra domir, pérdida } \\
\text { in reduccón de la }\end{array}$ & $\begin{array}{l}\text { atretto y pesa. } \\
\text { otencie o lss }\end{array}$ \\
\hline $\begin{array}{l}\text { Tersion } \\
\text { musoda }\end{array}$ & mend bila, dokr & catezs, dolor \\
\hline $\begin{array}{l}\text { Cambios } \\
\text { ogitacior }\end{array}$ & $\begin{array}{l}\text { estado de árimo: } \\
\text { oniss, pánico }\end{array}$ & odad, depresion \\
\hline $\begin{array}{l}\text { Tention } \\
\text { alerto }\end{array}$ & Sdo imegular del c & ain, fols de \\
\hline Difiouta & ra concentrarsey & rdar cosas \\
\hline Prancis & ducts agresing y. & ts \\
\hline Picoods o & Uts dal conejmo n & tiso de altas dosk \\
\hline Dafocer & al purmarerte & \\
\hline $\begin{array}{l}\text { Dafor } \\
\text { bins por }\end{array}$ & $\begin{array}{l}\text { 2, hemcriaga ca } \\
\text { mededes cartion }\end{array}$ & $\begin{array}{l}\text { L. mueris npan. } \\
\text { bes azualis }\end{array}$ \\
\hline
\end{tabular}

\section{F I Inhalantes}

Su riesgo de exporimencar estos danos es imarque unat

Beio Doderodo $\quad$ Nto

E consumo regula de irhalantes est $b$ acociado con:

Shtomas sembjartes a los de la gripe, sinusitis, sangrodo de nariz

Nbsses y vómito, indigestión, úloeras estomscales, darrsa

Mareos y alucinaciones, nausoa, alvtargamiento, desorientsción, visión borrosa

Dolores de cabeza acoidentes y lesiones, conducts impredeoble y peligross

Dificultades para la coordinacion, roucciones Ientas, poco abustociniento de axigeno al cuerpo

Perdida de la memcria, confusion, depresión agresion, carsarkio extromo

Delivio, corvulsiones, coma, dano en los organos (coradon pulmones, higado, rincones)

Muerte por insuficiencis cardisca 


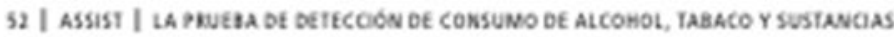

\begin{tabular}{|c|c|c|}
\hline \multicolumn{3}{|c|}{$\begin{array}{l}\text { Su riesgo de experimentar estos dahos es imarque } \\
\text { uno) }\end{array}$} \\
\hline 8sjo & Moderado & Alto \\
\hline \multicolumn{3}{|c|}{ El consumo regular de sedentes esta ascósbo con: } \\
\hline \multicolumn{3}{|c|}{ Aletargamiento, mareo y confusion } \\
\hline \multicolumn{3}{|c|}{ Dificulad para concentrarse y recordar cosas } \\
\hline \multicolumn{3}{|c|}{ Nesses, dolores de cabeza, paso inestable } \\
\hline \multicolumn{3}{|c|}{ Problemas para dormir } \\
\hline \multicolumn{3}{|c|}{ Ansiedad y depresion } \\
\hline \multicolumn{3}{|c|}{$\begin{array}{l}\text { Tolersnois y dependencis después de un } \\
\text { periodo corto de tismpo }\end{array}$} \\
\hline \multicolumn{3}{|c|}{ Sintomas de abstinencia severos } \\
\hline \multicolumn{3}{|c|}{$\begin{array}{l}\text { Sobeedosis y muerte si se coreumen con } \\
\text { alcohol, opisc6os y otras drogas depresives }\end{array}$} \\
\hline
\end{tabular}

\section{H I Aucinogenos}

Su riesgo de experimentar estos datos es imarque unot

Bajo Moderado Dito

E coroumo regular de abxinógenso esta asodiado con:

Cambios visusles, axditives, tóctiles y olletivos. conducts imoredecible

Dificulad pers dormit

Nissea y vomito

Toquicardis y alto presión sampines

Cambios del estado de ínimo

Ansiodad, párico, paranola

Visiones retrospectivas

Empeoramiento de los sintomas de enfermedades mertales, como esquinotreria

\section{Oplaceos}

Su riespo de euperimertar estos dahos es imarque uno):

\begin{tabular}{|l|l|l|}
\hline Bejo & Moderado
\end{tabular}

E corcuma regiter de cpifceos ests asociado con:

Comezón, nbuses y vímito

Alctargamiento, constipadon, caries, periodos menstruales irreglares

Dificultad para concentrarse y recordar cosas

Depresión, dsminuobón del impubo secusl. impotencía

Dificultades sconomicas, comidon de deitos

Estrets en las relgciones persongles

Problemas para conservar al trabajo y on ta

vida forrifor

Toletancia, dependencis, shorome de abstinsncia

Sobredosis y muerte por paro cardieco 
Apéndice C. Consentimiento informado para la participación de la investigación

\section{CONSENTIMIENTO INFORMADO PARA LA PARTICIPACIÓN DE INVESTIGACIÓN TOMA DE DECISIONES EN ADOLESCENTES COLOMBIANOS POLICONSUMIDORES}

Yo, , identificado con cédula de ciudadanía número de actuando en mi calidad de representante legal del menor , manifiesto a ustedes mi aceptación de mi participación en la investigación Toma de decisiones en adolescentes colombianos policonsumidores, realizada por el psicólogo estudiante de Maestría en Psicología de la Universidad Católica de Colombia.

He recibido una explicación clara sobre el carácter general y los propósitos del presente estudio. Estoy enterado (a) que con ello no se pretende hacer un diagnóstico o intervención clínica, no tendrá repercusiones en el futuro, sino los resultados arrojados serán utilizados únicamente para fines académicos. Soy consciente que tengo derecho a saber los resultados de las pruebas aplicadas si lo solicito.

También, tengo conocimiento que de acuerdo con lo establecido en el Código de Procesamiento Civil y en el Código Deontológico del Psicólogo, la totalidad de la información concerniente a mi representado es confidencial y no será divulgada ni entregada a alguna institución o individuo sin mi consentimiento expreso. Entiendo y por lo tanto estoy de acuerdo con la necesidad de quebrantar este principio de confidencialidad en caso de presentarse situaciones que pongan en grave peligro la integridad física o mental de mí representado (a) o de algún miembro de la comunidad. Por lo tanto, se valorará la gravedad de la situación para establecer el límite que permitirá quebrantar el principio de confidencialidad, pero que no tiene que contar con mi aceptación expresa.

Por último, se me ha informado que mi hijo (a) puede desistir de su participación en el momento que lo decida.

Firma

C.C

Fecha 
Apéndice D. Asentimiento informado para la participación de la investigación

\section{ASENTIMIENTO INFORMADO PARA LA PARTICIPACIÓN DE INVESTIGACIÓN TOMA DE DECISIONES EN ADOLESCENTES COLOMBIANOS POLICONSUMIDORES}

Yo, identificado con tarjeta de identidad número de manifiesto a ustedes mi aceptación de participar en la investigación Toma de decisiones en adolescentes colombianos policonsumidores, realizada por el psicólogo Universidad Católica de Colombia. estudiante de Maestría en Psicología de la

He recibido una explicación clara sobre el carácter general y los propósitos del presente estudio. Estoy enterado (a) que con ello no se pretende hacer un diagnóstico o intervención clínica, no tendrá repercusiones en el futuro, sino los resultados arrojados serán utilizados únicamente para fines académicos. Soy consciente que tengo derecho a saber los resultados de las pruebas aplicadas si lo solicito.

También, tengo conocimiento que de acuerdo con lo establecido en el Código de Procesamiento Civil y en el Código Deontológico del Psicólogo, la totalidad de la información es confidencial y no será divulgada ni entregada a alguna institución o individuo sin mi consentimiento expreso. Entiendo y por lo tanto estoy de acuerdo con la necesidad de quebrantar este principio de confidencialidad en caso de presentarse situaciones que pongan en grave peligro mi integridad física o mental de algún miembro de la comunidad. Por lo tanto, se valorará la gravedad de la situación para establecer el límite que permitirá quebrantar el principio de confidencialidad, pero que no tiene que contar con mi aceptación expresa.

Por último, se me ha informado que puedo desistir de la participación en el momento que lo decida.

Firma

C.C

Fecha 
Apéndice E. Protección de datos personales- HABEAS DATA

\section{LEY ESTATUTARIA 1266 de 2008 PROTECCIÓN DE DATOS PERSONALES - HABEAS DATA}

Mediante la cual autorizo en los términos de la presente ley, de manera libre, expresa y voluntaria a dar tratamiento de los datos suministrados por mí en el marco de la investigación.

Acuerdo 002 de 04 de septiembre de 2013.

$\begin{array}{lll}\text { Autorizo } & \mathrm{Si} & \text { No }\end{array}$

Firma

C.C

Fecha 
Apéndice F. Tabla preprogramada lowa Gambling Task

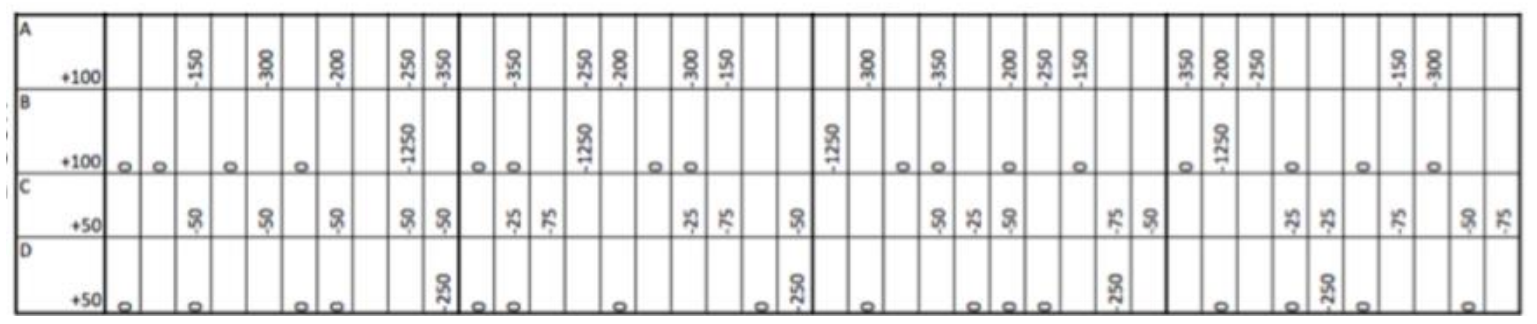

